\title{
Nucleus Accumbens Shell and mPFC but Not Insula Orexin-1 Receptors Promote Excessive Alcohol Drinking
}

\author{
Kelly Lei, Scott A. Wegner, Ji Hwan Yu, Arisa Mototake, Bing Hu and Frederic W. Hopf* \\ Alcohol and Addiction Research Group, Department of Neurology, University of California, San Francisco, San Francisco, CA, \\ USA
}

\section{OPEN ACCESS}

Edited by:

Brian McCool,

Wake Forest School of Medicine, USA

Reviewed by:

Rodrigo España,

Drexel University College of Medicine,

USA

Marcelo F. Lopez, Medical University of South Carolina

USA

Stephen V. Mahler,

University of California, Irvine, USA

*Correspondence:

Frederic W. Hopf

Frederic.Hop@@ucsf.edu

Specialty section:

This article was submitted to

Neuropharmacology,

a section of the journal

Frontiers in Neuroscience

Received: 09 May 2016 Accepted: 15 August 2016

Published: 30 August 2016

Citation:

Lei K, Wegner SA, Yu JH, Mototake A, Hu B and Hopf FW (2016) Nucleus Accumbens Shell and mPFC but Not Insula Orexin-1 Receptors Promote

Excessive Alcohol Drinking.

Front. Neurosci. 10:400. doi: 10.3389/fnins.2016.00400
Addiction to alcohol remains a major social and economic problem, in part because of the high motivation for alcohol that humans exhibit and the hazardous binge intake this promotes. Orexin-1-type receptors (OX1Rs) promote reward intake under conditions of strong drives for reward, including excessive alcohol intake. While systemic modulation of OX1Rs can alter alcohol drinking, the brain regions that mediate this OX1R enhancement of excessive drinking remain unknown. Given the importance of the nucleus accumbens (NAc) and anterior insular cortex (alNS) in driving many addictive behaviors, including OX1Rs within these regions, we examined the importance of OX1Rs in these regions on excessive alcohol drinking in C57BL/6 mice during limited-access alcohol drinking in the dark cycle. Inhibition of OX1Rs with the widely used SB-334867 within the medial NAc Shell (mNAsh) significantly reduced drinking of alcohol, with no effect on saccharin intake, and no effect on alcohol consumption when infused above the mNAsh. In contrast, intra-mNAsh infusion of the orexin-2 receptor TCS-OX2-29 had no impact on alcohol drinking. In addition, OX1R inhibition within the alNS had no effect on excessive drinking, which was surprising given the importance of alNS-NAc circuits in promoting alcohol consumption and the role for alNS OX1Rs in driving nicotine intake. However, OX1R inhibition within the mPFC did reduce alcohol drinking, indicating cortical OXR involvement in promoting intake. Also, in support of the critical role for mNAsh OX1Rs, $\mathrm{SB}$ within the $\mathrm{mNAsh}$ also significantly reduced operant alcohol self-administration in rats. Finally, orexin ex vivo enhanced firing in mNAsh neurons from alcohol-drinking mice, with no effect on evoked EPSCs or input resistance; a similar orexin increase in firing without a change in input resistance was observed in alcohol-naïve mice. Taken together, our results suggest that OX1Rs within the mNAsh and $\mathrm{mPFC}$, but not the alNS, play a central role in driving excessive alcohol drinking.

Keywords: alcohol, nucleus accumbens shell, insula, orexin, SB-334867

\section{INTRODUCTION}

Addiction to abused substances, including alcohol, is characterized by strong motivation for the addictive substance (Larimer et al., 1999; Sinha, 2009; Koob and Volkow, 2010). However, despite extensive efforts, alcohol use disorders (AUDs) remain a significant problem with substantial personal, social, and economic costs (Harwood et al., 1998; Blincoe et al., 2002; Mokdad et al., 2004; Dawson et al., 2005; Hingson et al., 2005; Rehm et al., 2009; Bouchery et al., 2011; Sacks et al., 2013; CDC, 2014; SAMHSA, 2014), 
especially because of the limited pharmacotherapies that are effective against AUDs (Spanagel, 2009; WHO, 2014).

Orexin receptors (OXRs) are of particular interest for addictive behaviors since they can promote intake of a number of motivating and addictive substances (Mahler et al., 2012, 2014; Boutrel et al., 2013; Barson and Leibowitz, 2016). OXRs are activated by the neuropeptide orexin, which is synthesized in a subset of cells in the lateral hypothalamus that project throughout the brain (de Lecea et al., 1998), and mediate a variety of regulatory and homeostatic behaviors ranging from sleep-wake cycle and neuroendocrine regulation to feeding and arousal (Mahler et al., 2014; Brown J. A. et al., 2015; Li et al., 2016). Orexin can act through OX1-type or OX2-type receptors (OX1Rs or OX2Rs), and although both receptors can contribute to addictive behaviors (Mahler et al., 2012), existing studies suggest that OX1Rs play a much more important overall role relative to OX2Rs (Moorman and Aston-Jones, 2009; Baimel et al., 2014; Barson et al., 2014; Mahler et al., 2014; Brown J. A. et al., 2015; but see Brown et al., 2013; Anderson et al., 2014). In particular, OX1Rs have been implicated in driving the pursuit and intake of high-value, salient natural rewards, such as sucrose and high-fat foods, as well as addictive substances such as cocaine, opioids, nicotine, and alcohol, with little role in sustaining consumption of less motivating substances (Borgland et al., 2009; Cason et al., 2010; Baimel et al., 2014; Mahler et al., 2014). For example, OX1Rs mediate greater alcohol preference and intake in rats (Moorman and Aston-Jones, 2009) and increased alcohol drinking in dependent mice (Lopez et al., 2016). Thus, OX1R signaling could represent an important and novel clinical and therapeutic target for intervention for AUDs (Khoo and Brown, 2014; Li et al., 2016).

While considerable evidence implicates OX1Rs in driving intake of preferred rewards, the brain regions that mediate this effect on alcohol drinking are poorly understood. We recently demonstrated that projections from the anterior insula (aINS) to the nucleus accumbens (NAc) are critical for driving compulsionlike alcohol drinking in rats (Seif et al., 2013). The medial Shell subregion of the NAc (mNAsh) also plays an important role in a promoting a number of addictive and other motivated behaviors (Anderson et al., 2008; Chaudhri et al., 2010; Saddoris et al., 2013; Castro et al., 2015; Corbit and Balleine, 2015; Marchant et al., 2015; Millan et al., 2015), including a role for mNAsh OXRs during feeding and morphine-related behavior (Thorpe and Kotz, 2005; Qi et al., 2013; Sadeghzadeh et al., 2016), although there have been mixed results regarding the presence of OX1Rs within the mNAsh (See Section Discussion). The aINS is also thought to play a central role in driving addictive behaviors in both humans (Naqvi et al., 2014) and animals (Hollander et al., 2008; Seif et al., 2013), and OX1Rs within the aINS promote nicotine intake (Hollander et al., 2008). In addition, OX1Rs in the $\mathrm{MPFC}$ have been shown to increase alcohol relapse (Brown R. M. et al., 2015). Thus, we examined whether OX1Rs in the mNAsh, aINS, and mPFC were important for driving excessive alcohol drinking in mice, and whether mNAsh OX1Rs promoted responding for alcohol in rats. We also used electrophysiology to assess whether OX1Rs altered measures of mNAsh activity ex vivo.

\section{METHODS}

\section{Animals}

All procedures followed the Guide for Care and Use of Laboratory Animals provided by the National Institutes of Health, and with approval of the Institutional Animal Care and Use Committee of UCSF. Male C57BL/6 mice, 7-8-week of age, were purchased from Jackson Laboratories. Mice were singlehoused under a reverse 12:12 light:dark cycle, with lights off at 10:00 a.m. Male Long-Evans rats, 45-50 days of age, were purchased from Harlan and singly housed, and housed under a standard light-dark cycle (with drinking experiments performed in the light cycle). Food and water were available, ad libitum, for all subjects. We used mice because of their higher level of drinking under two-bottle intake relative to rats. In contrast, operant methods in mice are much more challenging, and thus we utilized operant methods in rats.

\section{Limited Daily Access (LDA) to Alcohol in Mice}

The repeated, limited access choice alcohol drinking model was modified from that previously described (Lesscher et al., 2010; Kasten and Boehm, 2014). Mice were first acclimated to housing conditions for 2-week. Mice were then given twobottle choice access to one bottle with 15\% alcohol (v/v) in water and a second bottle of water. Mice first had a 24-h overnight alcohol-drinking session, followed by a 24$\mathrm{h}$ withdrawal period. Thereafter, mice were presented daily with $15 \%$ alcohol and water for 2 -h, Monday-Friday, in their home cage, with drinking sessions starting 3-h into the dark cycle. This excessive-drinking exposure paradigm leads to binge levels of alcohol drinking (>80 mg\%) (Lei et al., 2016). In order to control for side preference, the bottle placements of the solutions were alternated between each drinking session. Intake level was measured by determining bottle weight and corrected for spill, which was determined by separate spillcontrol bottles.

\section{Saccharin Intake in Mice}

Drinking of a $0.05 \%$ saccharin solution under two-bottle choice was performed using a schedule identical to that used for alcohol. This concentration was determined to give approximately the same volume of intake as alcohol (e.g., $19.2 \pm 2.3 \mathrm{ml} / \mathrm{kg} / 2$-h of alcohol intake for vehicle condition in Figure 1B; $t_{(1,27)}=1.54$, $p=0.14$ vs. volume of saccharin intake for vehicle condition in Figure 2B).

\section{Alcohol Self-administration in Rats}

Rat self-administration methods were identical to those previously described (Simms et al., 2011b), using standard operant conditioning chambers (MedAssociates). Briefly, rats underwent six 14-h overnight session on an FR1 schedule, with $0.1 \mathrm{ml}$ of $20 \%$ alcohol delivered after each FR1 press. During overnight training, only the active lever was available, which allowed the establishment of lever-pressing behavior. Rats then had six sessions of 45 -min FR1, and then were moved to a daily 30-min FR3 schedule of responding; a second, inactive 


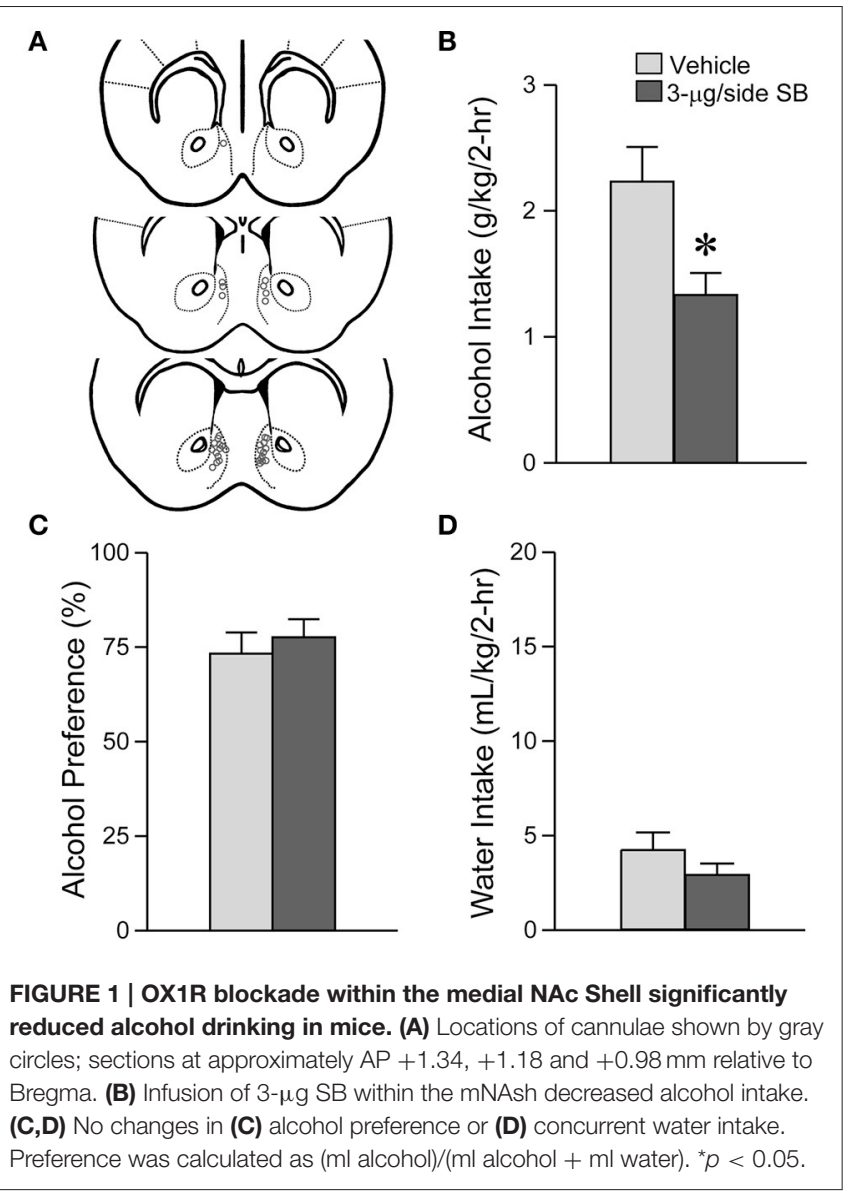

lever was also introduced during the FR3 sessions. In all phases of training, successful completion of an FR response resulted in alcohol delivery as well as a cue light above the active lever and a tone. Inactive lever presses were not accompanied by alcohol delivery or light or tone cues. Rats pressed for a minimum of 20 sessions before testing the impact of SB on responding for alcohol. Any animal receiving less $0.3 \mathrm{~g} / \mathrm{kg}$ ethanol intake per session were excluded (one rat in this study).

\section{Cannula Implantation Surgeries}

In mice, after $\sim 2$-week of LDA, surgery was performed to implant bilateral guide cannulae (Plastics One) aimed at the mNAsh (AP $+1.5, \mathrm{ML} \pm 0.5, \mathrm{DV}-4.5 \mathrm{~mm}$ ), an offsite control region above the mNAsh (AP $+1.5, \mathrm{ML} \pm 0.5, \mathrm{DV}-3.0 \mathrm{~mm})$, aINS (AP +2.0, $\mathrm{ML} \pm 2.4, \mathrm{DV}-2.0 \mathrm{~mm}$ ), and the mPFC (attempting to target the infralimbic) (AP $+1.7, \mathrm{ML} \pm 0.4$, DV $-2.7 \mathrm{~mm}$ ). In rats, after establishing FR3 responding, bilateral guide cannulae were implanted targeting the mNAsh ( $\mathrm{AP}+1.8$, $\mathrm{ML} \pm 0.8, \mathrm{DV}-6.5 \mathrm{~mm}$ ). All coordinates are given relative to Bregma. After surgery, animals were allowed to recover for 1-week before resuming alcohol drinking sessions, and handling for drug microinfusions began the week after. After completion of drug treatments, brains were harvested for verification of cannula placement.

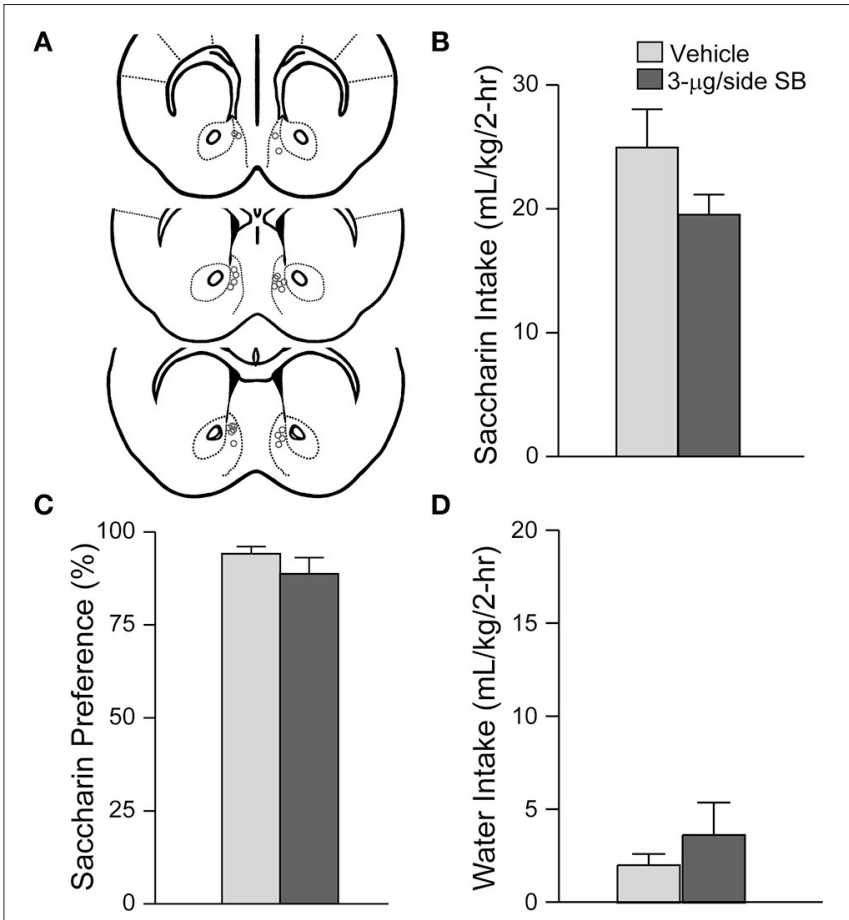

FIGURE 2 | mNAsh OX1R blockade did not alter saccharin drinking. (A) Locations of cannulae, as for Figure 1. (B-D) Infusion of $3-\mu \mathrm{g}$ SB within the mNAsh did not alter (B) saccharin intake, (C) preference or (D) concurrent water intake.

\section{Drug Microinfusions}

SB-334867 (SB, Tocris), a selective OX1R antagonist, was dissolved in 100\% DMSO vehicle (Simms et al., 2011a). Mice received microinjections of either vehicle or $3-\mu \mathrm{g} / 200 \mathrm{~nL} /$ side $(47 \mathrm{nmol})$ of SB 30 -min prior to an alcohol-drinking session, or $3-\mu \mathrm{g} / 200 \mathrm{~nL} / \mathrm{side}(59 \mathrm{nmol})$ of the OX2R antagonist TCSOX2-29 (TCS, Tocris); these are relatively high doses but have previously been utilized (Borgland et al., 2006; Qi et al., 2013; Brown R. M. et al., 2015). Drugs were injected with bilateral infusion needles (Plastics One) that projected $0.3 \mathrm{~mm}$ past the end of the guide cannulae, at a rate of $200 \mathrm{~nL} / \mathrm{min}$. Needles were left in place for an extra 1-min before retraction. Each dose (vehicle and 3- $\mu \mathrm{g}$ SB or TCS) was microinjected twice (on different test days) and counter-balanced across treatment and animals.

Rats received microinjections of either 0 - or $3-\mu \mathrm{g} / 600 \mathrm{~nL} / \mathrm{side}$ of $\mathrm{SB}$, on different days using a within-animal design in a counterbalance manner, 30-min prior to alcohol self-administration sessions. Drugs were injected $600 \mathrm{~nL} / \mathrm{min}$ via bilateral infusions needles (Plastics One) that project $1-\mathrm{mm}$ beyond the guide cannulae. Needles were left in place for an extra 90-s.

Mice or rats were given at least 1 day of alcohol or saccharin drinking between test days.

Alcohol intake, especially bottle drinking, can be influenced by handling (Lum et al., 2014), and thus it is important to give animals a period of time after injection to remove possible confounds of handling on alcohol drinking, and we used a $30 \mathrm{~min}$ 
time point between drug injection and behavioral testing. Thus, given the use of DMSO as a vehicle for SB, we cannot completely rule out the possibility that this period of time might have allowed greater diffusion of OXRS to adjacent brain regions, for example into the adjacent NAcore. However, even if a briefer time was used between injection and initiation of alcohol drinking, the drinking sessions were $2 \mathrm{~h}$ and any such issues related to diffusion would become apparent within the first hour of drinking. Also, although we do not have specific information about the level of spread of our infusate, $200 \mathrm{nl}$ has previously used as an microinjection volume for studies distinguishing mNAsh vs. NAcb Core in mice (Managò et al., 2008), and is widely used as a volume for injection for other studies in mice (e.g., Stratford and Wirtshafter, 2011; Kasten and Boehm, 2014; Ramaker et al., 2015).

DMSO as vehicle could have effects on drinking. However, alcohol intake in the presence of intra-mNAsh DMSO infusion was not different from alcohol drinking levels in the uninjected days adjacent to days with DMSO infusion [DMSO infusion: $2.23 \pm 0.28 \mathrm{~g} / \mathrm{kg}$; adjacent uninjected days: $2.31 \pm 0.23 \mathrm{~g} / \mathrm{kg}$; $t_{(1,16)}=0.26, p=0.80 ; n=17$, determined for the mice shown in Figure 1, DMSO results are same as shown in Figure 1]. Also, other studies have demonstrated that intracranial injection of DMSO does not have non-specific effects on behavior relative to saline injection (e.g., Naghdi and Asadollahi, 2004). Thus, the DMSO vehicle itself likely did not have non-specific effects on alcohol drinking.

\section{Brain Slice Preparation and Ex vivo Electrophysiology}

Slice preparation and electrophysiology methods were similar to those previously described (Seif et al., 2011, 2013; Pomrenze et al., 2015). Briefly, adult mice were anesthetized with pentobarbital $(100 \mathrm{mg} / \mathrm{kg})$, decapitated, and brain slices were cut in an icecold glycerol-based solution (in mM: 252 glycerol, $2.5 \mathrm{KCl}, 1.25$ $\mathrm{NaH}_{2} \mathrm{PO}_{4}, 1 \mathrm{MgCl}_{2}, 2 \mathrm{CaCl}_{2}, 25 \mathrm{NaHCO}_{3}, 1 \mathrm{~L}$-ascorbate, and 11 glucose, bubbled with carbogen) (Pomrenze et al., 2015). Slices recovered at $32^{\circ} \mathrm{C}$ in carbogen-bubbled aCSF (containing, in mM: $126 \mathrm{NaCl}, 2.5 \mathrm{KCl}, 1.2 \mathrm{NaH}_{2} \mathrm{PO}_{4}, 1.2 \mathrm{MgCl}_{2}, 2.4$ $\mathrm{CaCl}_{2}, 18 \mathrm{NaHCO}_{3}, 11$ glucose, $\mathrm{pH}$ 7.2-7.4, mOsm 302-305) for at least $30 \mathrm{~min}$ before experiments, with $1 \mathrm{mM}$ ascorbic acid added just before the first slice. During experiments, slices were submerged and perfused $(2 \mathrm{ml} / \mathrm{min})$ with aCSF, $31-32^{\circ} \mathrm{C}$, with CNQX $(10 \mu \mathrm{M})$ and picrotoxin $(50 \mu \mathrm{M})$. Action potential firing and EPSCs were recorded using Clampex 10.1 and an Axon 700 A patch amplifier (Axon Instruments, Foster City, CA). All experiments were performed using whole-cell recording using visualized infrared-DIC with 2.5-3.5 M electrodes.

Firing and input resistance were measured using a potassiummethanesulfonate based internal solution (in $\mathrm{mM}: 130 \mathrm{KOH}$, 105 methanesulfonic acid, $17 \mathrm{HCl}, 20$ HEPES, 0.2 EGTA, 2.8 $\mathrm{NaCl}, 2.5 \mathrm{mg} / \mathrm{ml} \mathrm{Mg-ATP,} 0.25 \mathrm{mg} / \mathrm{ml} \mathrm{GTP}$ pH 7.2-7.4, 278-287 mOsm). DC current was passed to bring each neuron to $85 \mathrm{mV}$ before starting firing experiments. Rheobase (minimum current needed to generate firing) was first identified for each cell by a series of $500 \mathrm{~ms}$ current steps, increasing in $20 \mathrm{pA}$ increments, which was then terminated once rheobase was identified. We then began experiments where a more restricted set of $500 \mathrm{~ms}$ current steps (6-7 steps, 20 pA apart, with the first pulse subthreshold for firing) which were repeated every $30 \mathrm{~s}$ to measure possible changes in firing across the duration of the experiment. Depolarizing pulses alternated with a $30 \mathrm{pA}$ hyperpolarizing pulse to examine the input resistance. Changes in firing and input resistance with $10 \mathrm{~min}$ of orexinA application $(100 \mathrm{nM})$ was determined after $\sim 15 \mathrm{~min}$ baseline, with $\mathrm{SB}$ added $5 \mathrm{~min}$ before orexinA exposure in some cells.

To determine orexinA-related changes in firing, we averaged $7 \mathrm{~min}$ of baseline, and averaged the last $7 \mathrm{~min}$ of the 10 min orexinA exposure (since it usually takes $2-3 \mathrm{~min}$ before a drug effect is clear); we then subtracted the average number of action potentials generated during orexinA exposure from average number of spikes at baseline. This was determined at rheobase, the minimum current where firing was evoked, and at the current step above rheobase. Rheobase was $168 \pm 24$ pA (range: 100-320 pA) for experiments from alcohol-drinking mice, and $185 \pm 22 \mathrm{pA}$ (range: $125-240 \mathrm{pA}$ ) for alcohol-naïve experiments.

EPSCs were measured using a cesium-methanesulfonate based internal solution (in mM: 120 cesium methanesulfonate, 20 HEPES, 0.4 EGTA, $2.8 \mathrm{NaCl}, 5$ TEA chloride, $2.5 \mathrm{Mg}$ ATP, 0.25 Na-GTP, pH 7.2-7.3, 270-285 mOsm). EPSCs were filtered at $2 \mathrm{kHz}$ and digitized at $10 \mathrm{kHz}$. Series resistance (10$30 \mathrm{M} \Omega$ ) and input resistance were monitored on-line using a 4-mV depolarizing step $(50 \mathrm{~ms})$ which was given after every EPSC. Electrically-evoked currents were elicited using a bipolar stimulating electrode placed $\sim 200 \mu \mathrm{M}$ dorsal to the recording site. As with firing, $7 \mathrm{~min}$ of baseline and orexinA exposure were used for determining the percent change in EPSCs with orexinA.

Statistics for electrophysiology experiments were performed either using an unpaired $t$-test, to compare changes in firing in orexin-exposed neurons with or without SB pre-exposure, or using a paired $t$-test, to examine whether orexin exposure altered input resistance or EPSCs relative to pre-orexin baseline under a particular condition.

\section{Data Analyses for Behavioral Studies}

In mice, after each drinking session, the water and alcohol (or saccharin) bottles were weighed; subsequently, these values were used to determine the intake of alcohol ( $\mathrm{g} / \mathrm{kg}$ of body weight) or saccharin $(\mathrm{mL} / \mathrm{kg}$ of body weight), as well as water $(\mathrm{ml} / \mathrm{kg}$ of body weight) and the preference ratio for the alcohol or saccharin (volume of reward intake/total volume of reward plus water intake). Due to variability of two-bottle choice alcohol drinking in mice, each mouse had two test sessions for vehicle and two test sessions for OXR blocker, and the average of the two drinking sessions for each treatment was used for a given animal. Importantly, all such tests were performed in a counterbalanced order: a mouse received vehicle vs. drug in a counterbalanced order for the first two test sessions, such that half the animals received vehicle in the first session, and the other half received OXR blocker in the first session. The same counterbalanced order 
was then used for the third and fourth test sessions, to insure that animals did not receive the same treatment in consecutive sessions, and to minimize the order effects. Rats received one test session of vehicle or SB, which was counterbalanced across animals, and active and inactive lever pressing, rewards received, and $\mathrm{g} / \mathrm{kg}$ intake levels, were all determined. Finally, since the effects of vehicle and drug were tested within the same animal, all statistics for behavioral experiments were performed using a paired $t$-test, using SPSS (IBM). Different behavioral measures were assessed by separate paired $t$-tests. All data are shown as mean \pm SEM.

In our experience, alcohol intake levels in daily two-bottle choice sessions are more variable relative to operant responding, and bottle drinking in mice is more variable than in rat. Thus, we have adopted the method in mice where vehicle is tested twice and the two sessions averaged, and a given agent is tested twice then averaged. In addition, to determine test-retest variance, we examined the data for intra-mNAsh vehicle vs. SB during alcohol drinking. We first calculated the difference between the second-vehicle and first-vehicle test sessions that an animal underwent, or between the seconddrug and first-drug test sessions. The standard deviation of test-retest was $2.54 \mathrm{~g} / \mathrm{kg}$ for vehicle and $1.35 \mathrm{~g} / \mathrm{kg}$ for SB. Although the test-retest variability was larger for vehicle, animals drank an average of $2.23 \mathrm{~g} / \mathrm{kg}$ alcohol for vehicle sessions and $1.33 \mathrm{~g} / \mathrm{kg}$ alcohol for SB sessions. Thus, the somewhat larger test-retest variability for vehicle sessions may reflect the larger volume of intake during vehicle sessions. In addition, to assess order effects, we performed a two-way RM ANOVA with drug vs. vehicle as one factor and the first vs. second test session of the given agent as a second factor. There were no significant effects of first vs. second session $\left[F_{(1,32)}=1.647\right.$, $p=0.209]$, or interaction of session number with group [vehicle or drug; $F_{(1,32)}=0.009, p=0.924$ ], although there was a significant effect of group $\left[F_{(1,32)}=7.602\right.$, $p=0.010]$, consistent with our previous analysis that SB in the mNAsh reduced alcohol drinking relative to vehicle. These findings suggest that there were no differences in intake between the first and second test sessions for either vehicle or drug.

One limitation of the present experiments is the possibility that some experiments may be underpowered to observe a change in intake with OXR blockers, e.g., the trend for intra-mNAsh $\mathrm{SB}$ to decrease in intake in saccharin-consuming mice with $n=12$ vs. $n=17$ for alcohol-drinking mice. However, we were able to observe a significant depression of alcohol drinking in mice where $\mathrm{SB}$ was injected into the $\mathrm{MPFC}$, with $n=9$, suggesting that saccharin-intake experiments were sufficiently powered to detect any OXR-relate changes. For the off-site control experiments, it is clear even with $n=6$ that there is no impact of SB on alcohol drinking, and if anything there is a trend for an increase in preference for alcohol (rather than inhibition of alcohol-related behavior). Nonetheless, with the smaller sample size, the off-site control group could be underpowered to detect differences in alcohol drinking.

\section{RESULT}

\section{OX1R Blockade in the Medial NAc Shell Suppressed Excessive Alcohol Drinking in Mice}

We first examined whether OX1Rs in the mNAsh could regulate voluntary excessive alcohol drinking. In particular, we microinjected vehicle or a previously used concentration of the OX1R-selective antagonist, SB-334867 (SB, 3- $\mu \mathrm{g} / \mathrm{side}$ ) (Hollander et al., 2008; Espana et al., 2010; Plaza-Zabala et al., 2012), prior to an LDA drinking session using a counterbalanced, within-animal design $(n=17)$. Our results showed that inhibition of OX1Rs within the mNAsh (Figure 1A) significantly decreased alcohol drinking [Figure 1B; $t_{(1,16)}=$ 2.78, $p=0.013]$. No changes were observed in preference [Figure 1C; $t_{(1,16)}=0.58, p=0.57$ ], which likely reflects the low volume of concurrent water intake during the 2 -h alcoholdrinking sessions [Figure 1D; $t_{(1,16)}=1.50, p=0.15$; see also Dhaher et al., 2009; Seif et al., 2015; den Hartog et al., 2016]. Thus, our results suggest that OX1Rs within the mNAsh are important for driving alcohol drinking.

Suppression of alcohol drinking by the OX1R antagonist in the mNAsh might represent non-specific changes in motor function or consumption. Thus, we next examined whether SB within the mNAsh (Figure 2A) would reduce intake of $0.05 \%$ saccharin $(n=12)$. However, $3-\mu \mathrm{g}$ of SB within the mNAsh had no effect on saccharin consumption [Figure 2B; $t_{(1,11)}=1.68, p=0.12$ ], preference [Figure 2C; $t_{(1,11)}=0.97, p=0.35$ ], or concurrent water intake [Figure 2D; $t_{(1,11)}=0.77, p=0.46$ ]. Thus, the suppression of alcohol drinking when infusing OX1R inhibitors within the mNAsh was likely due to a particular role in promoting alcohol drinking, rather than through more general regulation of consumption or activity. However, we do note that there was a trend for a decrease in saccharin intake with intra-mNAsh SB infusion.

To assess the possible involvement of OX2Rs in alcohol drinking, we tested whether injection of the OX2R blocker TCSOX2-29 $(3-\mu \mathrm{g})$ into the mNAsh (Figure 3A; $n=13$ ) would alter excessive alcohol consumption, similar to what we observed with intra-mNAsh SB. However, TCS within the mNAsh did not reduce alcohol intake [Figure 3B; $t_{(1,12)}=1.94, p=0.08$ ], and if anything had a trend to increase intake. TCS within the mNAsh also did not alter preference [Figure 3C; $t_{(1,12)}=0.14, p=0.89$ ] or concurrent water intake [Figure 3D; $t_{(1,12)}=1.27, p=0.23$ ]. These results indicate that OX1Rs but not OX2Rs within the mNAsh were important for promoting excessive alcohol drinking in mice.

To test whether SB could affect alcohol drinking by diffusing and acting in a region adjacent to the mNAsh, we administered the same dose and vehicle into an off-site control region $1.5-\mathrm{mm}$ dorsal to the mNAsh ( $n=6$; Figure 4A). However, no changes in alcohol intake were observed when 3- $\mu \mathrm{g}$ SB was injected into the off-site region control group [Figure 4B; $t_{(1,5)}=0.04$, $p=0.97$ ], and with no change in alcohol preference [Figure 4C; $t_{(1,5)}=2.22, p=0.077$ ] or concurrent water intake [Figure 4D; $\left.t_{(1,5)}=1.56, p=0.18\right]$. Thus, the apparent mNAsh OX1R 


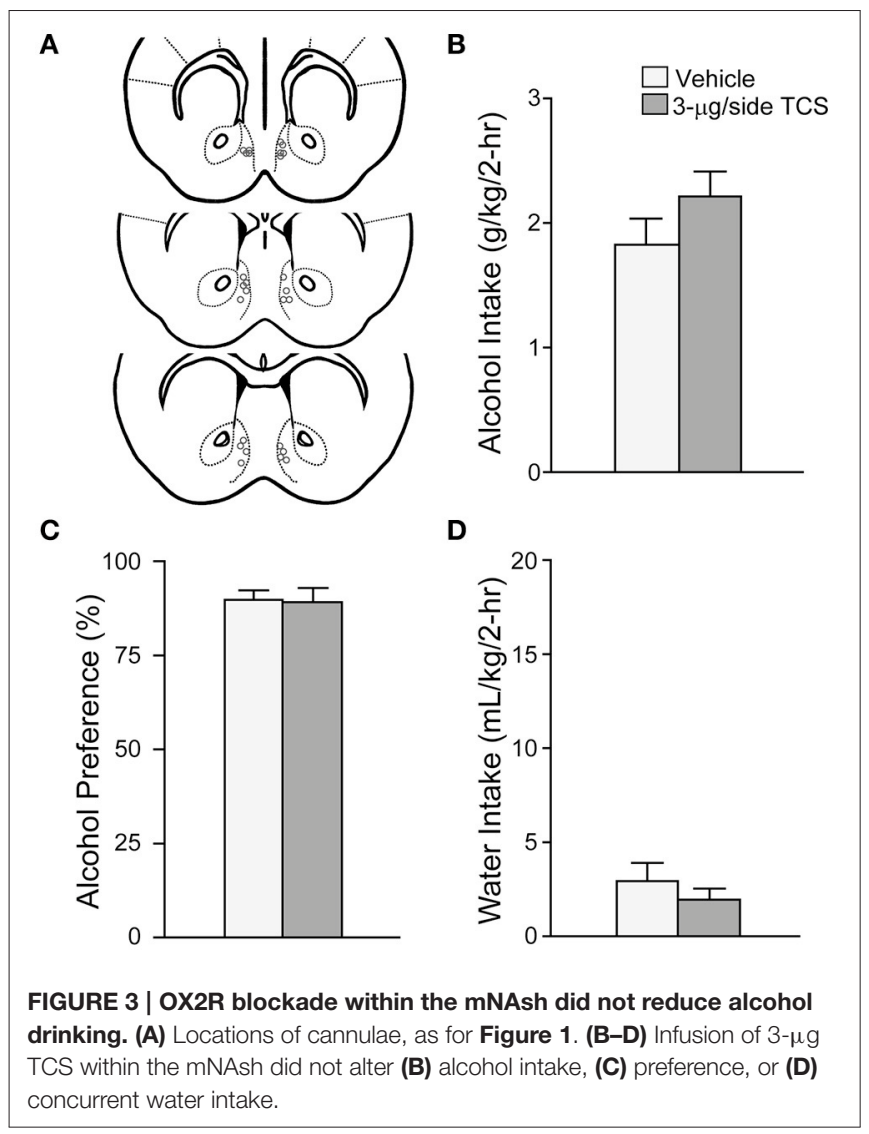

promotion of alcohol drinking was unlikely to reflect action of $\mathrm{SB}$ in brain areas above the mNAsh.

In addition to the mNAsh, the aINS likely plays a central role in promoting many addiction-related behaviors. Thus, we also examined whether OX1Rs within the aINS would promote alcohol drinking $(n=9)$ (Figure 5A), as was observed for OX1Rs within the mNAsh (Figure 1). However, infusion of SB within the aINS had no effect on alcohol intake [Figure 5B; $t_{(1,8)}=0.03$, $p=0.98$ ], preference [Figure 5C; $t_{(1,8)}=0.17, p=0.87$ ] or concurrent water intake [Figure 5D; $t_{(1,8)}=0.73, p=0.49$ ]. Thus, contrary to our predictions, OX1Rs within the aINS did not play a role in promoting alcohol drinking in mice.

Finally, other cortical areas have also been implicated in regulating alcohol drinking, including the medial prefrontal cortex. In agreement, we found that infusion of 3- $\mu \mathrm{g}$ SB within the $\mathrm{mPFC}$ (Figure 6A; $n=9$ ) significantly reduced alcohol drinking [Figure 6B; $t_{(1,8)}=2.34, p=0.048$ ], with no impact on preference [Figure $6 \mathrm{C} ; t_{(1,8)}=0.75, p=0.47$ ] or concurrent water intake [Figure 6D; $t_{(1,8)}=1.69, p=0.13$ ]. Thus, our results together suggest that $\mathrm{MPFC}$ but not aINS OX1Rs are important for promoting alcohol drinking.

\section{NAsh OX1R Blockade Decreased Lever Pressing for Alcohol in Rats}

Since OX1R inhibition within the mNAsh of mice significantly reduced alcohol drinking, we next examined whether mNAsh OX1Rs would be important for promoting alcohol intake under a

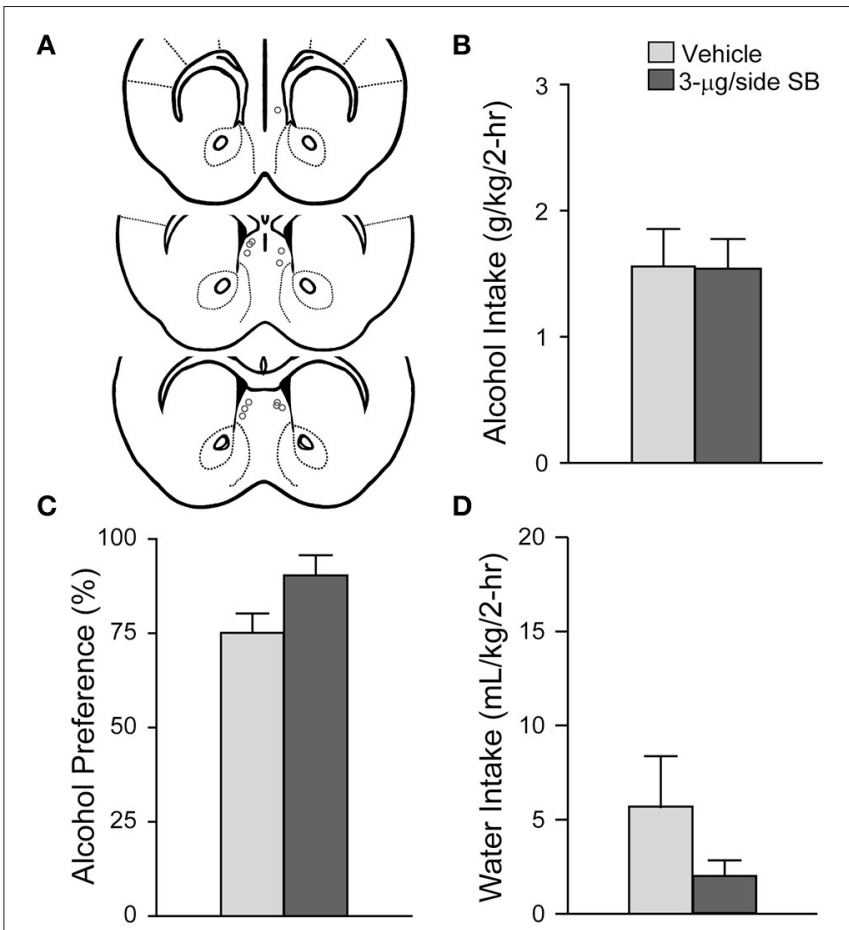

FIGURE 4 | OX1R blockade at an off-site control above the mNAsh did not alter alcohol drinking. (A) Locations of cannulae, as for Figure 1. (B-D) Infusion of 3- $\mu \mathrm{g}$ SB $\sim 1.5 \mathrm{mM}$ above the mNAsh did not alter (B) alcohol intake, (C) preference, or (D) concurrent water intake.

different drinking model, operant responding for alcohol in rats $(n=8)$ (Figure 7A). In fact, inhibition of OX1Rs within the mNAsh of rats with $3-\mu \mathrm{g}$ SB significantly reduced lever-pressing for alcohol, tested within-rat vs. vehicle [Figure 7B; $t_{(1,7)}=$ $4.17, p=0.004$ ], with an $\sim 40 \%$ reduction, similar to what was observed in mice. OX1R inhibition had no effect on pressing of the inactive lever [Figure $7 \mathrm{C} ; t_{(1,7)}=1.34, p=0.22$ ], although this was already very low. In addition, OX1R inhibition within the mNAsh significantly reduced the number of rewards received [Figure 7D; $t_{(1,7)}=2.95, p=0.021$ ] and the amount of alcohol consumed [Figure $7 \mathbf{E} ; t_{(1,7)}=2.84, p=0.025$ ]. Thus, OX1Rs in the mNAsh were critical for promoting alcohol consumption in both mice and rats.

\section{OrexinA Peptide Enhanced mNAsh Action Potential Firing through OX1Rs}

Since OX1Rs within the mNAsh were important for promoting alcohol drinking, we next examined whether orexin would impact mNAsh firing ex vivo in brain slices from adult alcoholdrinking mice. In fact, firing evoked by depolarizing current pulses was significantly enhanced in the presence of orexinA $(100 \mathrm{nM}, n=5)$, which was apparent when analyzing both at rheobase, the minimum current required to evoke action potentials in a cell [Figures 8A,B; paired $t_{(4)}=6.54, p=$ 0.003], and at the current step above rheobase [Figure 8C; paired $\left.t_{(4)}=5.35, p=0.006\right]$. Importantly, this effect of orexinA was prevented by inhibition of OX1Rs with SB $[3 \mu \mathrm{M}$, 


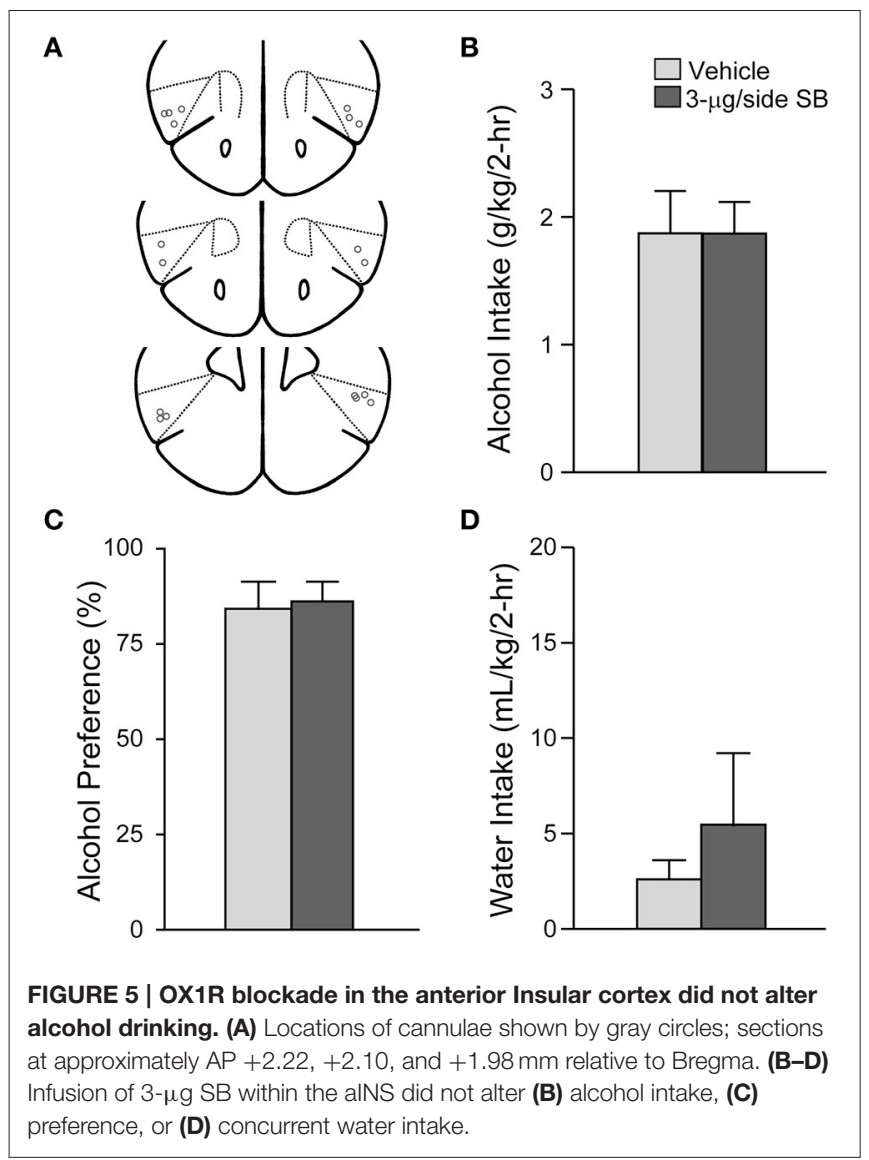

$n=4$; Figures 8B,C; orexinA application with vs. without SB: $t_{(7)}=4.09, p=0.005$ at rheobase; $t_{(7)}=2.91$, $p=0.023$ at step above rheobase]. The orexinA increase in firing was not accompanied by any changes in input resistance, measured using a hyperpolarizing current pulse at resting potential [Figures 9A,B; $2.3 \pm 2.7 \%$ change in R-input; paired $\left.t_{(4)}=1.26, p=0.28\right]$. In addition, orexinA did not alter EPSCs generated at a $-70 \mathrm{mV}$ resting potential [Figure 9C; $n=$ 6 ; $-3.7 \pm 6.5 \%$ change in EPSC; paired $t_{(5)}=0.21, p=$ 0.84]; this EPSC predominantly reflects AMPA receptor currents (Seif et al., 2013). Together, these results suggest that OX1Rs enhanced mNAsh activity in alcohol-drinking mice through altering intrinsic excitability but not glutamatergic function at $-70 \mathrm{mV}$.

We also examined whether orexinA would alter firing in mNAsh neurons from alcohol-naïve mice. OrexinA (100 nM) significantly increased action potential firing by $1.6 \pm 0.5$ spikes at rheobase [paired $t_{(4)}=3.30, p=0.03 ; n=5$ ], which was not different from the orexin change in firing in alcoholdrinking mice [from Figure 8B; unpaired $t_{(8)}=0.01, p=$ 0.99]. In addition, in agreement with results from alcoholdrinking mice, the orexin enhancement in firing in alcoholnaive mice was not accompanied by any changes in input resistance [baseline: $307 \pm 49 \mathrm{M} \Omega$; orexin: $320 \pm 48 \mathrm{M} \Omega$; $4.7 \pm 4.6 \%$ change in input resistance; paired $t_{(4)}=1.20$, $p=0.30]$. Thus, orexin enhanced action potential firing in
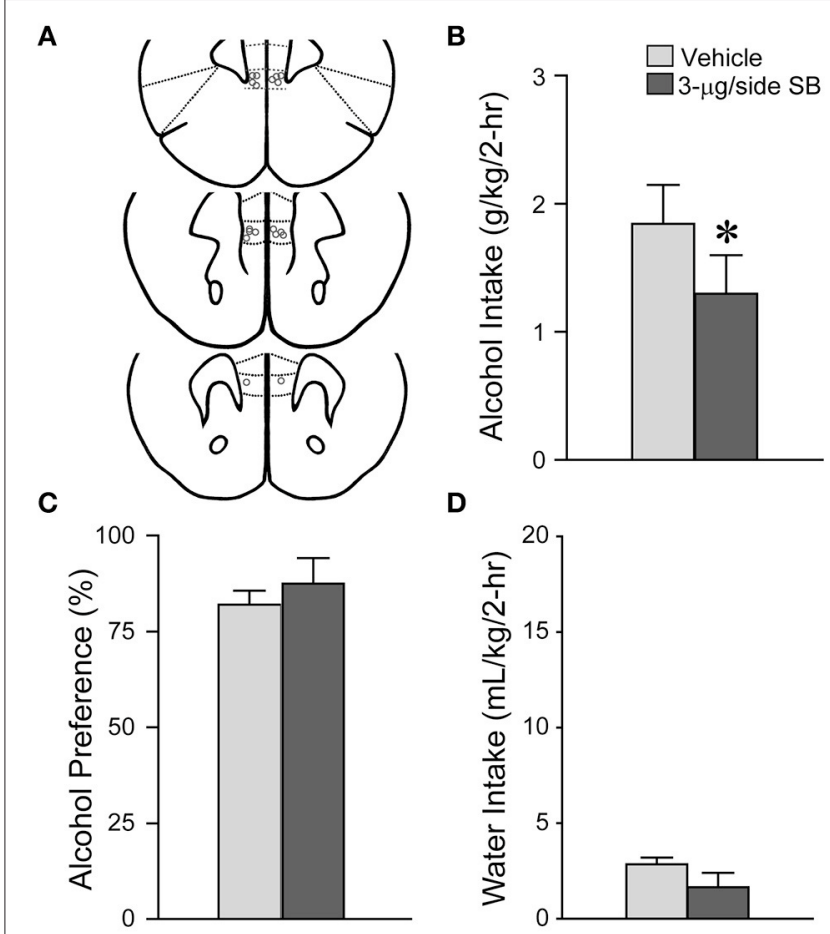

FIGURE 6 | OX1R blockade in the MPFC significantly reduced alcohol drinking. (A) Locations of cannulae shown by gray circles; sections at approximately $\mathrm{AP}+1.98,+1.78$, and $+1.70 \mathrm{~mm}$ relative to Bregma. (B) Infusion of 3- $\mu \mathrm{g}$ SB within the mPFC decreased alcohol intake. (C,D) No changes in (C) alcohol preference or (D) concurrent water intake. ${ }^{*} p<0.05$.

mNAsh neurons from both alcohol-naive and alcohol-drinking mice.

\section{DISCUSSION}

Alcohol addiction is a significant economic and social problem, in part due to the strong motivation for alcohol that persons with AUDs exhibit. OX1Rs promote intake when there is strong drive for a reward, but the brain region(s) that mediate the OX1R promotion of excessive alcohol drinking remain largely unknown. Here, we demonstrate that the medial NAc Shell (mNAsh) is a critical region where OX1Rs act to promote excessive alcohol intake in mice. Inhibition of OX1Rs within the mouse mNAsh had no effect on consumption of saccharin or concurrent water drinking during alcohol drinking sessions, suggesting that mNAsh OX1R regulation of excessive alcohol intake was not due to nonspecific effects on motor activity or consumption. In addition, inhibition of OX2Rs within the mNAsh did not alter alcohol intake, suggesting a receptorselective effect within the mNAsh. In addition, OX1R inhibition at an off-site control region above the mNAsh did not alter alcohol drinking. Surprisingly, OX1R inhibition within the mouse aINS also had no effect on excessive alcohol intake drinking, although aINS-NAc circuits are known to promote alcohol consumption and aINS OX1Rs drives nicotine intake. In contrast, OX1Rs within the mPFC did promote alcohol 

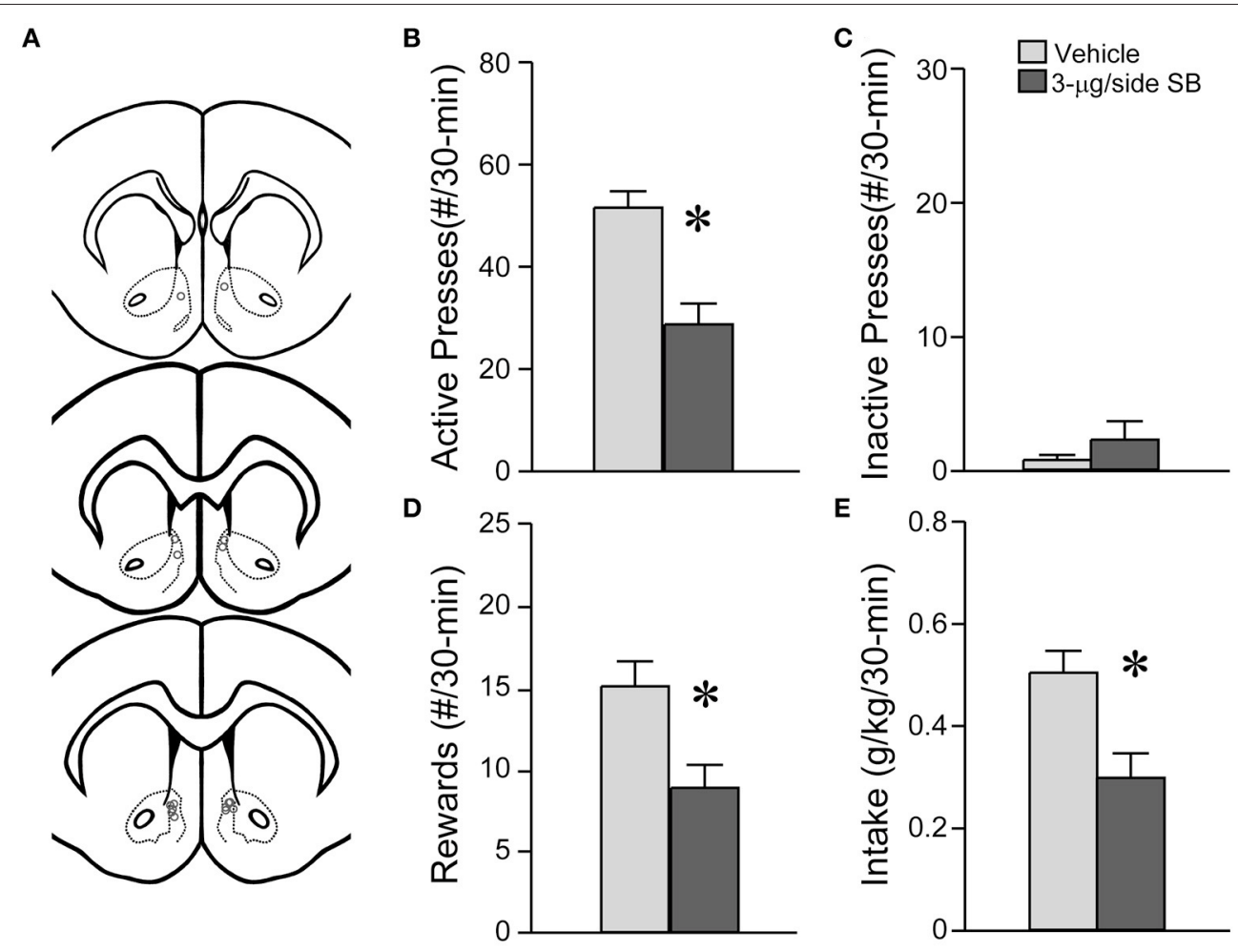

FIGURE 7 | OX1R blockade within the medial NAc Shell significantly reduced operant alcohol drinking in rats. (A) Locations of cannulae shown by gray circles; sections at approximately AP $+1.70,+1.60$, and +1.20 relative to Bregma. (B) Infusion of $3-\mu \mathrm{g}$ SB within the mNAsh of rats decreased active lever presses for alcohol. (C) No changes in inactive lever presses with SB. (D,E) OX1R inhibition in the mNAsh reduced (D) rewards received and (E) alcohol intake levels. ${ }^{\star} p<0.05$.

consumption. Further supporting the central role for mNAsh OX1Rs in promoting alcohol drinking, OX1R inhibition within the mNAsh of rats significantly reduced operant alcohol selfadministration. Finally, orexin application ex vivo significantly enhanced action potential firing of mNAsh neurons from alcohol-drinking mice, with no changes in input resistance or evoked EPSCs. Together, our results suggest that the mNAsh and $\mathrm{mPFC}$, but not the aINS, are critical regions where OX1R activation drives excessive alcohol drinking.

While a number of studies suggest that OX1Rs play a prominent and selective role in responding for more motivating rewards (See Section Introduction), very little is known about the brain regions where OX1Rs act to promote excessive alcohol drinking. Here, we did not assess motivation directly, but instead examined the impact of orexin on drinking behaviors. Our findings are important since they identify the mNAsh as a region where OX1Rs drive alcohol consumption in both mice and rats. In addition, our studies indicate that OX2Rs within the mNAsh are not required to promote excessive alcohol consumption. Previous work has implicated the mNAsh in different forms of addictive and consummatory behaviors, including feeding (Baldo et al., 2013; Richard et al., 2013) and alcohol drinking (Kasten and Boehm, 2014; Lum et al., 2014; Wilden et al., 2014; Ramaker et al., 2015). The mNAsh also promotes different forms of reinstatement (Anderson et al., 2008), including for alcohol (Chaudhri et al., 2010; Marchant et al., 2015), although, under conditions of extinction, inhibiting the mNAsh promotes relapse for alcohol (Millan et al., 2010). However, cortical activation of the mNAsh promotes reinstatement of opiate conditioned place preference (CPP) (Hearing et al., 2016) and seeking (Bossert et al., 2015), and OXRs within the mNAsh also contribute to expression and reinstatement of morphine CPP (Qi et al., 2013; Sadeghzadeh et al., 2016). Thus, although the mNAsh contribution can vary depending on the addictive behavior, these studies overall concur with our findings that OX1Rs in the mNAsh promote alcohol drinking in vivo and increase neuronal activity ex vivo (see below).

In contrast to the central role for mNAsh OX1Rs in driving alcohol consumption, OX1Rs within the aINS seemed to play no role in alcohol drinking. This was surprising because the aINS is thought to drive many addictive behaviors in both humans (Naqvi et al., 2014) and animals (Hollander et al., 2008; Seif et al., 2013), including compulsion-like alcohol drinking (Seif et al., 2013), and OX1Rs within the aINS mediate nicotine intake (Hollander et al., 2008). Thus, inasmuch as the aINS can promote alcohol drinking, it is likely that signaling systems other than OX1Rs within the aINS are required to promote addictive behavior. Also, OX1Rs in the medial prefrontal cortex promote cued reinstatement for alcohol in genetically-selected alcoholpreferring rats (Brown R. M. et al., 2015). In agreement, we found that mPFC OX1Rs were also important for promoting alcohol intake. Thus, our studies have identified critical regions of the 


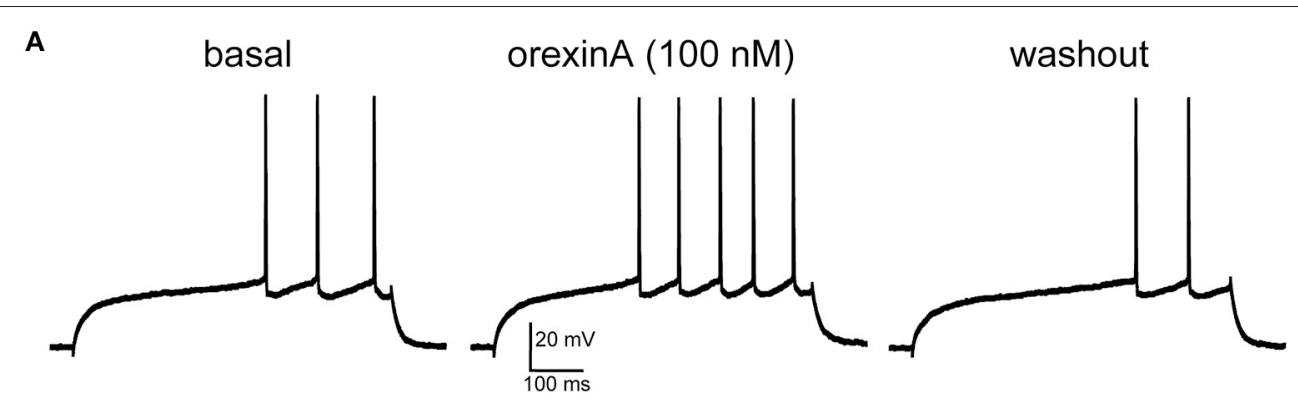

B

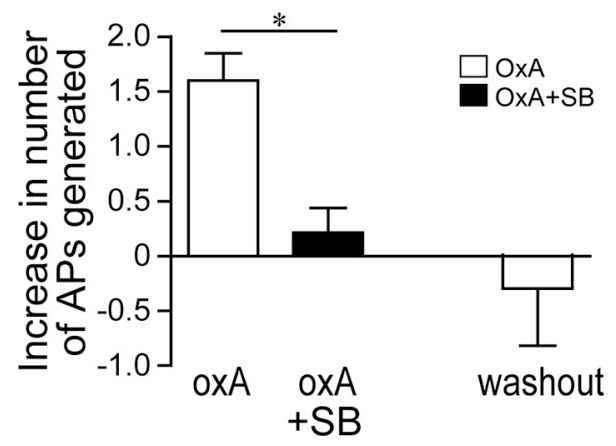

C

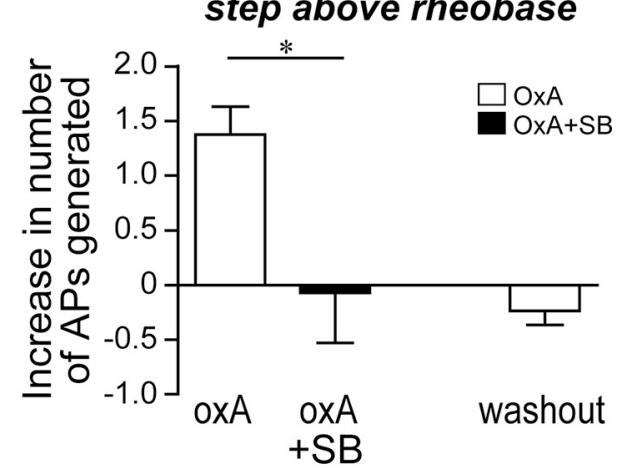

FIGURE 8 | OrexinA increased firing ex vivo in medial NAc Shell neurons from alcohol-drinking mice. (A) Example showing that 100 nM orexinA (OxA) increased firing in the mNAsh neurons from adult alcohol-drinking mice; firing was evoked by 500-ms depolarizing current pulses (See Section Methods). Example is from rheobase, the minimum current required to evoke firing, in this neuron (B,C) Averaged data showing the increased number of action potentials generated with OxA (B) at rheobase, and (C) at the current step above rheobase, and that blocking OX1Rs with SB prevented the OxA increase in firing. ${ }^{\star} p<0.05$.

cortico-accumbens circuit where OX1Rs act to promote excessive alcohol drinking.

Since the mNAsh can regulate feeding, including OXRs within the mNAsh (Thorpe and Kotz, 2005; Urstadt and Stanley, 2015; but see Baldo and Kelley, 2001), the reduction of alcohol consumption after inhibiting mNAsh OX1Rs could reflect more general effects on motor and consumption. However, intramNAsh OX1R inhibition had no effect on saccharin consumption or concurrent water intake during alcohol-drinking sessions, suggesting that mNAsh OX1Rs play a more specific role in driving alcohol consumption. In agreement, previous studies found no change in chow intake or locomotor activity when OX1Rs were inhibited in the mNAsh (Thorpe and Kotz, 2005; Kotani et al., 2008; Qi et al., 2013). In addition, several studies implicating the mNAsh in alcohol drinking also observed no reduction in intake of sweet substances (Stratford and Wirtshafter, 2011; Rewal et al., 2012; Kasten and Boehm, 2014; Lum et al., 2014). Thus, although there was a trend for a decrease in saccharin intake in our results with intra-mNAsh $\mathrm{SB}$ infusion, it is more likely that this does not reflect an actual but underpowered decrease. Also, we found that mNAsh OX1R inhibition significantly reduced alcohol drinking but not preference, which likely reflects the low level of concurrent water intake during the alcohol access session (a similar pattern is also observed in Dhaher et al., 2009; Seif et al., 2015; den Hartog et al., 2016). Thus, while mNAsh signaling can contribute to many consummatory behaviors, our findings suggest that OX1Rs within the mNAsh play a particular role in promoting excessive alcohol drinking.

In agreement with our observations that OX1R mNAsh promoted excessive alcohol drinking, we found that the orexin ex vivo enhanced action potential firing in mNAsh neurons from alcohol-drinking mice, and that this orexin increase in activity required OX1Rs. In contrast, there were no changes in evoked glutamatergic EPSCs, perhaps suggesting a primarily postsynaptic effect of orexin excitation within the mNAsh. In addition, orexin increased evoked firing with no changes in input resistance at the resting membrane potential. Interestingly, enhancement in mNAsh firing without changes at the hyperpolarized resting potential is similar to what has been reported for dopamine enhancement of mNAsh firing (Hopf et al., 2003). In agreement, NAc dopamine receptors regulate alcohol drinking and seeking (Bahi and Dreyer, 2012; Hauser et al., 2015), and dopamine receptors have been shown to interact with orexin to enhance mNAsh firing ex vivo (Mori et al., 2011). However, previous studies of orexin enhancement of mNAsh firing suggest a role for OX2Rs (Mukai et al., 2009; Mori et al., 2011), although these were performed in very young (12-16 d) animals, while our work was performed in adult neurons. Also, we did not find a role for OX2Rs within the mNAsh in promoting alcohol drinking. However, other work suggests that OX2Rs can interact with OX1Rs under some conditions, e.g., where either OX1R or OX2R inhibition in the mNAsh can suppress reinstatement of morphine CPP (Qi et al., 2013). Also, 


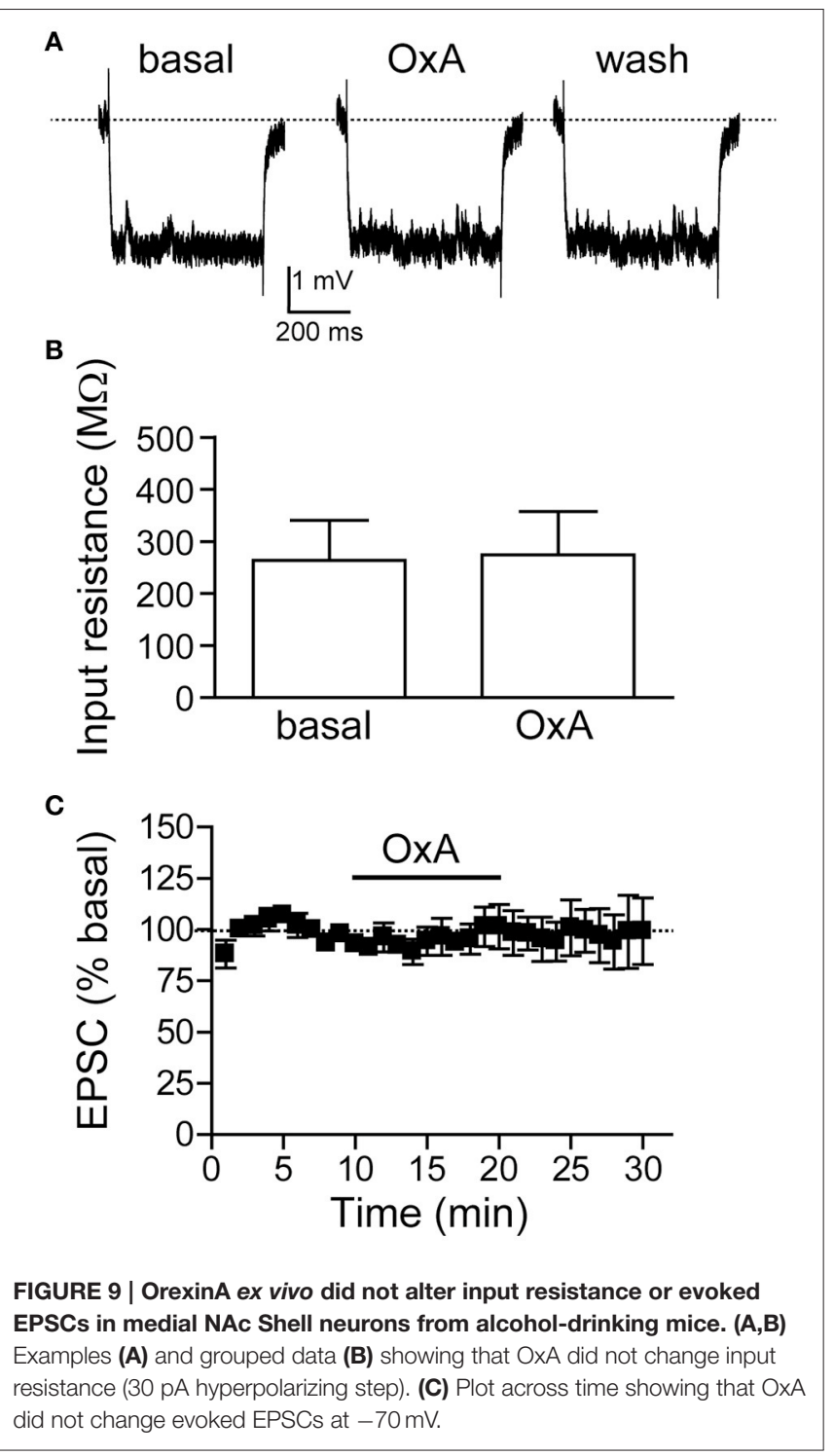

orexin enhancement of locomotion may be related to OX2Rs but not OX1Rs in the mNAsh (Thorpe and Kotz, 2005; Kotani et al., 2008), suggesting that mNAsh OX1Rs and OX2Rs can have differential effects. Furthermore, passive high alcohol exposures produce plasticity within the NAc Shell (Renteria et al., 2016), but we found that orexin enhanced firing ex vivo without changes in input resistance in both alcohol-drinking and alcohol-naïve mice. Nonetheless, understanding the ex vivo impact of orexinA is most critical in alcohol drinkers, since this physiological impact would be more relevant to the ability of mNAsh OX1Rs to drive alcohol intake.

It is also important to understand whether the ability of OX1Rs to enhance mNAsh postsynaptic firing, but not glutamatergic activation, has a more general implication for behavioral regulation by the mNAsh. Our observation that OX1Rs increased mNAsh activity and promoted alcohol drinking are in overall agreement with previous studies using agents that inhibit neuronal function, such as GABA receptor agonists, where mNAsh inhibition decreases alcohol drinking (e.g., Stratford and Wirtshafter, 2011; Kasten and Boehm, 2014; Ramaker et al., 2015). While these studies do not demonstrate the postsynaptic function per se is the primary site of action, it is very likely that the behavioral impact of these compounds reflects inhibition of the NAc neuron activity that is known to promote behavioral expression in a number of other paradigms (e.g., McGinty et al., 2013; Pascoli et al., 2014). Thus, any action of orexin (or other neurochemicals) that increases activity of NAc neurons could promote behavioral expression of alcohol drinking. In addition, enhancement of mNAsh firing or glutamatergic activity could increase excitatory throughput of the mNAsh and increase behavioral expression, especially since NAc neurons postsynaptic firing is strongly dependent on glutamatergic excitation (Gerfen and Surmeier, 2011). Thus, while modulation of specific glutamatergic inputs to the mNAsh could alter specific aspects of behavior (e.g., Pascoli et al., 2014), it remains unclear what selective effects that overall modulation of firing vs. glutamatergic activation would have. Finally, we found that mNAsh OX1Rs did not significantly regulate intake of saccharin, in agreement with other work finding no reduction in intake of sweet substances after mNAsh inhibition (see above). In fact, increased intake of sweet and other highly palatable substances has been associated with strong inhibition of the mNAsh rather than excitation (Richard et al., 2013). In contrast, mNAsh OXRs have been associated with increased food intake in some, although not all, studies (Baldo and Kelley, 2001; Thorpe and Kotz, 2005; Urstadt and Stanley, 2015). Thus, the neuronal pathway activated by mNAsh OX1Rs seems to play a more selective impact on intake of certain substances (alcohol, food), with perhaps a very different role for other substances (sweets); this might provide insight into the specific consummatory pathways co-opted by drives for alcohol.

It is important to note there have been mixed results regarding whether there are OX1Rs present in the NAshell and striatum, and that the OX1R-related blocker SB can still impact OX2Rs, although at lower affinity relative to OX1Rs (Smart et al., 2001). Importantly, however, our intracranial pharmacology experiments directly demonstrate that inhibition of OX1Rs but not OX2Rs within the mNAsh significantly reduced excessive alcohol drinking. These suggest that OX1Rs but not OX2Rs within the mNAsh promote excessive drinking. Nonetheless, while some studies have found some OX1R mRNA signal within the medial NAc (D’Almeida et al., 2005) and striatum (Hervieu et al., 2001, NAc not tested), others did not (Trivedi et al., 1998; Marcus et al., 2001). Also, a recent study utilizing a transgenic OX1R-GFP mouse found no OX1R-containing neurons within the NAc (Ch'ng and Lawrence, 2015). We note that mRNA levels do not always predict functional protein expression (e.g., as observed for OX1Rs for some brain regions described in Table 1 of Ch'ng and Lawrence, 2015). Also, small levels of receptor expression may be sufficient to allow functional signaling. e.g., where overlap of DA1R-cell and DA2R-cell markers can be seen in at least $20 \%$ of striatal neurons by electrophysiology and the very sensitive single-cell RT-PCR (Surmeier et al., 1996), even though transgenic GFP-expressing lines show very little overlap of DA1R-cell and D2R-cell markers in striatal neurons 
(Gerfen and Surmeier, 2011). In addition, OxA infusion within the mNAsh enhances feeding, which is prevented by $\mathrm{SB}$, while OxA enhancement of locomotion is not prevented by SB (Thorpe and Kotz, 2005), indicating that SB can impact some but not all effects of OxA within the mNAsh, the remainder presumably reflecting action through OX2Rs. Also, development of morphine CPP is inhibited by SB but not OX2R inhibitors in the mNAsh (Sadeghzadeh et al., 2016). Finally, other studies have provided ex vivo evidence for functional OX1Rs within the mNAsh (Patyal et al., 2012), in addition to our demonstration of OX1Rdependent enhancement of mNAsh firing; we believe that these electrophysiological measures provide the most sensitive and direct method to assess the presence of functional receptors, in this case OX1Rs. Thus, since we directly demonstrated that inhibition of mNAsh OX2Rs with TCS had no impact on excessive alcohol drinking, our results taken together suggest that SB acts at OX1Rs within the mNAsh to suppress alcohol drinking. In addition, it is clear that the ability of OxR signaling to suppress alcohol drinking is region-specific, since both Insula and regions dorsal to the NAshell have Ox1Rs and OX2Rs, but SB within these regions had no impact on alcohol drinking. Finally, although our rat and mouse results implicate OX1R signaling within the mNAsh in promoting excessive alcohol drinking, we cannot completely rule out the possibility that the impact of intracranially infused SB inhibited alcohol drinking by action in a region medial or lateral to the mNAsh, such as the septum or NAc core. This is primarily a concern in mice, since we have previously shown that intra-mNAsh infusion in rats does not lead to effects within the adjacent NAc core, suggesting minimal effects of diffusion (Hopf et al., 2010). Also, the septum contains Ox1Rs although not mRNA for OX1Rs (see Wu et al., 2002; Ch'ng and Lawrence, 2015), while addiction-related orexin signaling has been associated with OX2Rs but not OX1Rs in the septum (Flores et al., 2016), and OX2Rs in the NAc core can regulate alcoholrelated behavior (Brown et al., 2013). In contrast, here we found that OX1Rs but not OX2Rs drove excessive alcohol drinking

\section{REFERENCES}

Anderson, R. I., Becker, H. C., Adams, B. L., Jesudason, C. D., and Rorick-Kehn, L. M. (2014). Orexin-1 and orexin-2 receptor antagonists reduce ethanol selfadministration in high-drinking rodent models. Front. Neurosci. 8:33. doi: 10.3389/fnins.2014.00033

Anderson, S. M., Famous, K. R., Sadri-Vakili, G., Kumaresan, V., Schmidt, H. D., Bass, C. E., et al. (2008). CaMKII: a biochemical bridge linking accumbens dopamine and glutamate systems in cocaine seeking. Nat. Neurosci. 11, 344-353. doi: 10.1038/nn2054

Bahi, A., and Dreyer, J. L. (2012). Involvement of nucleus accumbens dopamine D1 receptors in ethanol drinking, ethanol-induced conditioned place preference, and ethanol-induced psychomotor sensitization in mice. Psychopharmacology 222, 141-153. doi: 10.1007/s00213-011-2630-8

Baimel, C., Bartlett, S. E., Chiou, L. C., Lawrence, A. J., Muschamp, J. W., Patkar, O., et al. (2014). Orexin/hypocretin role in reward: implications for opioid and other addictions. Br. J. Pharmacol. 172, 334-348. doi: 10.1111/bph.12639

Baldo, B. A., and Kelley, A. E. (2001). Amylin infusion into rat nucleus accumbens potently depresses motor activity and ingestive behavior. Am. J. Physiol. Regul. Integr. Comp. Physiol. 281, R1232-R1242.

Baldo, B. A., Pratt, W. E., Will, M. J., Hanlon, E. C., Bakshi, V. P., and Cador, M. (2013). Principles of motivation revealed by the diverse functions of neuropharmacological and neuroanatomical substrates in mice. Further experiments, perhaps involving local infusion of inhibitory RNAs, will be required to fully dissociate whether areas adjacent to the mNAsh are important for regulating alcohol drinking.

Taken together, our studies indicate that OX1Rs within the mNAsh are critical for promoting excessive alcohol drinking, which may reflect the ability of orexin to increase action potential firing in an OX1R-dependent manner in mNAsh neurons from alcohol drinkers. In contrast, OX1Rs within the aINS did not regulate alcohol consumption, even though the aINS can regulate alcohol intake (Seif et al., 2013) and aINS OX1Rs can promote nicotine intake (Hollander et al., 2008). Since OX1Rs play a predominant role in driving motivated intake (see above), and excessive drinking in humans is driven by pathological drives for alcohol, our results suggest that the mNAsh is a key region where OX1Rs can promote excessive alcohol intake. Thus, OX1R inhibitors might represent a viable therapeutic intervention to suppress alcohol drinking in humans (Khoo and Brown, 2014; Li et al., 2016).

\section{AUTHOR CONTRIBUTIONS}

Study concept and design: KL, SW, FH. Acquisition of data: KL, SW, JY, AM, BH, FH; Statistical analyses and interpretation of data: KL, SW, FH; Preparation of manuscript: KL, FH.

\section{FUNDING}

Supported by NIAAA P50 AA017072.

\section{ACKNOWLEDGMENTS}

We thank Dr. Dorit Ron for critical review of this manuscript, Jeffrey A. Simms for assistance with rat behavior, and Molly Sazer-Hopf for assistance with brain section images.

underlying feeding behavior. Neurosci. Biobehav. Rev. 37, 1985-1998. doi: 10.1016/j.neubiorev.2013.02.017

Barson, J. R., Ho, H. T., and Leibowitz, S. F. (2014). Anterior thalamic paraventricular nucleus is involved in intermittent access ethanol drinking: role of orexin receptor 2. Addict. Biol. 20, 469-481. doi: 10.1111/adb.12139

Barson, J. R., and Leibowitz, S. F. (2016). Hypothalamic neuropeptide signaling in alcohol addiction. Prog. Neuropsychopharm. Biol. Psychiatry 65, 321-329. doi: 10.1016/j.pnpbp.2015.02.006

Blincoe, L., Seay, A., Zaloshnja, E., Miller, T., Romano, E., Luchter, S., et al. (2002). The Economic Impact of Motor Vehicle Crashes, 2000. Washington, DC: U.S. Department of Transportation, 1-82.

Borgland, S. L., Chang, S. J., Bowers, M. S., Thompson, J. L., Vittoz, N., Floresco, S. B., et al. (2009). Orexin A/hypocretin-1 selectively promotes motivation for positive reinforcers. J. Neurosci. 29, 11215-11225. doi: 10.1523/JNEUROSCI.6096-08.2009

Borgland, S. L., Taha, S. A., Sarti, F., Fields, H. L., and Bonci, A. (2006). Orexin A in the VTA is critical for the induction of synaptic plasticity and behavioral sensitization to cocaine. Neuron 49, 589-601. doi: 10.1016/j.neuron.2006.01.016

Bossert, J. M., Stern, A. L., Theberge, F. R., Marchant, N. J., Wang, H. L., Morales, M., et al. (2015). Role of projections from ventral medial prefrontal cortex to nucleus accumbens shell in context-induced reinstatement of heroin seeking. J. Neurosci. 32, 4982-4991. doi: 10.1523/JNEUROSCI.0005-12.2012 
Bouchery, E. E., Harwood, H. J., Sacks, J. J., Simon, C. J., and Brewer, R. D. (2011). Economic costs of excessive alcohol consumption in the U.S., 2006. Am. J. Prev. Med. 41, 516-524. doi: 10.1016/j.amepre.2011.06.045

Boutrel, B., Steiner, N., and Halfon, O. (2013). The hypocretins and the reward function: what have we learned so far? Front. Behav. Neurosci. 7:59. doi: 10.3389/fnbeh.2013.00059

Brown, J. A., Woodworth, H. L., and Leinninger, G. M. (2015). To ingest or rest? Specialized roles of lateral hypothalamic area neurons in coordinating energy balance. Front. Syst. Neurosci. 9:9. doi: 10.3389/fnsys.2015.00009

Brown, R. M., Khoo, S. Y., and Lawrence, A. J. (2013). Central orexin (hypocretin) 2 receptor antagonism reduces ethanol self-administration, but not cue-conditioned ethanol-seeking, in ethanol-preferring rats. Int. J. Neuropsychopharm. 16, 2067-2079. doi: 10.1017/S1461145713000333

Brown, R. M., Kim, A. K., Khoo, S. Y., Kim, J. H., Jupp, B., and Lawrence, A. J. (2015). Orexin-1 receptor signalling in the prelimbic cortex and ventral tegmental area regulates cue-induced reinstatement of ethanol-seeking in iP rats. Addict. Biol. 21, 603-612. doi: 10.1111/adb.12251

Cason, A. M., Smith, R. J., Tahsili-Fahadan, P., Moorman, D. E., Sartor, G. C., and Aston-Jones, G. (2010). Role of orexin/hypocretin in reward-seeking and addiction: implications for obesity. Physiol. Behav. 100, 419-428. doi: 10.1016/j.physbeh.2010.03.009

Castro, D. C., Cole, S. L., and Berridge, K. C. (2015). Lateral hypothalamus, nucleus accumbens, and ventral pallidum roles in eating and hunger: interactions between homeostatic and reward circuitry. Front. Syst. Neurosci. 9:90. doi: $10.3389 /$ fnsys. 2015.00090

CDC (2014). Excessive Drinking Costs U.S. \$223.5 Billion. Atlanta: Center for Disease Control.

Chaudhri, N., Sahuque, L. L., Schairer, W. W., and Janak, P. H. (2010). Separable roles of the nucleus accumbens core and shell in context- and cue-induced alcohol-seeking. Neuropsychopharmacology 35, 783-791. doi: 10.1038/npp.2009.187

Ch'ng, S. S., and Lawrence, A. J. (2015). Distribution of the orexin1 receptor (OX1R) in the mouse forebrain and rostral brainstem: a characterisation of OX1R-eGFP mice. J. Chem. Neuroanat. 66-67, 1-9. doi: 10.1016/j.jchemneu.2015.03.002

Corbit, L. H., and Balleine, B. W. (2015). Learning and motivational processes contributing to pavlovian-instrumental transfer and their neural bases: dopamine and beyond. Curr. Top. Behav. Neurosci. 27, 259-289. doi: 10.1007/7854_2015_388

D’Almeida, V., Hipolide, D. C., Raymond, R., Barlow, K. B., Parkes, J. H., Pedrazzoli, M., et al. (2005). Opposite effects of sleep rebound on orexin $\mathrm{OX}_{1}$ and $\mathrm{OX}_{2}$ receptor expression in rat brain. Mol. Brain Res. 136, 148-157. doi: 10.1016/j.molbrainres.2005.02.002

Dawson, D. A., Grant, B. F., and Li, T. K. (2005). Quantifying the risks associated with exceeding recommended drinking limits. Alcohol. Clin. Exp. Res. 29, 902-908. doi: 10.1097/01.ALC.0000164544.45746.A7

de Lecea, L., Kilduff, T. S., Peyron, C., Gao, X., Foye, P. E., Danielson, P. E., et al. (1998). The hypocretins: hypothalamus-specific peptides with neuroexcitatory activity. Proc. Natl. Acad. Sci. U.S.A. 95, 322-327. doi: 10.1073/pnas.95.1.322

den Hartog, C., Zamudio-Bulcock, P., Nimitvilai, S., Gilstrap, M., Eaton, B., Fedarovich, H., et al. (2016). Inactivation of the lateral orbitofrontal cortex increases drinking in ethanol-dependent but not non-dependent mice. Neuropharmacology 107, 451-459. doi: 10.1016/j.neuropharm.2016.03.031

Dhaher, R., Finn, D. A., Oberbeck, D. L., Yoneyama, N., Snelling, C. C., Wu, W., et al. (2009). Electrolytic lesions of the medial nucleus accumbens shell selectively decrease ethanol consumption without altering preference in a limited access procedure in C57BL/6J mice. Pharmacol. Biochem. Behav. 92, 335-342. doi: 10.1016/j.pbb.2008.12.024

Espana, R. A., Oleson, E. B., Locke, J. L., Brookshire, B. R., Roberts, D. C., and Jones, S. R. (2010). The hypocretin-orexin system regulates cocaine self-administration via actions on the mesolimbic dopamine system. Eur. J. Neurosci. 31, 336-348. doi: 10.1111/j.1460-9568.2009.07065.x

Flores, Á., Julià-Hernández, M., Maldonado, R., and Berrendero, F. (2016). Involvement of the orexin/hypocretin system in the pharmacological effects induced by $\Delta(9)$-tetrahydrocannabinol. Br. J. Pharmacol. 173, 1381-1392. doi: 10.1111/bph. 13440

Gerfen, C. R., and Surmeier, D. J. (2011). Modulation of striatal projection systems by dopamine. Annu. Rev. Neurosci. 34, 441-466. doi: 10.1146/annurev-neuro061010-113641
Harwood, H. J., Fountain, D., and Livermore, G. (1998). Economic costs of alcohol abuse and alcoholism. Recent Dev. Alcohol. 14, 307-330. doi: 10.1007/0-30647148-5_14

Hauser, S. R., Deehan, G. A. Jr., Dhaher, R., Knight, C. P., Wilden, J. A., McBride, W. J., et al. (2015). D1 receptors in the nucleus accumbens-shell, but not the core, are involved in mediating ethanol-seeking behavior of alcohol-preferring (P) rats. Neuroscience 295, 243-251. doi: 10.1016/j.neuroscience.2015. 03.030

Hearing, M. C., Jedynak, J., Ebner, S. R., Ingebretson, A., Asp, A. J., Fischer, R. A., et al. (2016). Reversal of morphine-induced cell-type-specific synaptic plasticity in the nucleus accumbens shell blocks reinstatement. Proc. Natl. Acad. Sci. U.S.A.113, 757-762. doi: 10.1073/pnas.1519248113

Hervieu, G. J., Cluderay, J. E., Harrison, D. C., Roberts, J. C., and Leslie, R. A. (2001). Gene expression and protein distribution of the orexin-1 receptor in the rat brain and spinal cord. Neuroscience 103, 777-797. doi: 10.1016/S03064522(01)00033-1

Hingson, R., Heeren, T., Winter, M., and Wechsler, H. (2005). Magnitude of alcohol-related mortality and morbidity among U.S. college students ages 1824: changes from 1998 to 2001. Ann. Rev. Public Health 26, 259-279. doi: 10.1146/annurev.publhealth.26.021304.144652

Hollander, J. A., Lu, Q., Cameron, M. D., Kamenecka, T. M., and Kenny, P. J. (2008). Insular hypocretin transmission regulates nicotine reward. Proc. Natl. Acad. Sci. U.S.A. 105, 19480-19485. doi: 10.1073/pnas.0808023105

Hopf, F. W., Bowers, M. S., Chang, S. J., Chen, B. T., Martin, M., Seif, T., et al. (2010). Reduced nucleus accumbens SK channel activity enhances alcohol seeking during abstinence. Neuron 65, 682-694. doi: 10.1016/j.neuron.2010.02.015

Hopf, F. W., Cascini, M. G., Gordon, A. S., Diamond, I., and Bonci, A. (2003). Cooperative activation of dopamine D1 and D2 receptors increases spike firing of nucleus accumbens neurons via G-protein betagamma subunits. J. Neurosci. 23, 5079-5087.

Kasten, C. R., and Boehm, S. L. II (2014). Intra-nucleus accumbens shell injections of $\mathrm{R}(+)$ - and $\mathrm{S}(-)$-baclofen bidirectionally alter binge-like ethanol, but not saccharin, intake in $\mathrm{C} 57 \mathrm{Bl} / 6 \mathrm{~J}$ mice. Behav. Brain Res. 272, 238-247. doi: 10.1016/j.bbr.2014.07.011

Khoo, S. Y., and Brown, R. M. (2014). Orexin/hypocretin based pharmacotherapies for the treatment of addiction: DORA or SORA? CNS Drugs 28, 713-730. doi: 10.1007/s40263-014-0179-x

Koob, G. F., and Volkow, N. D. (2010). Neurocircuitry of addiction. Neuropsychopharmacology 35, 217-238. doi: 10.1038/npp.2009.110

Kotani, A., Ikeda, H., Koshikawa, N., and Cools, A. R. (2008). Role of orexin receptors in the nucleus accumbens in dopamine-dependent turning behaviour of rats. Neuropharmacology 54, 613-619. doi: 10.1016/j.neuropharm.2007.11.006

Larimer, M. E., Palmer, R. S., and Marlatt, G. A. (1999). Relapse prevention. An overview of Marlatt's cognitive-behavioral model. Alcohol. Res. Health 23, 151-160.

Lei, K., Wegner, S. A., Yu, J.-H., Simms, J. A., and Hopf, F. W. (2016). A Single alcohol drinking session is sufficient to enable subsequent aversion-resistant consumption in mice. Alcohol. doi: 10.1016/j.alcohol.2016.07.008. [Epub ahead of print].

Lesscher, H. M., van Kerkhof, L. W., and Vanderschuren, L. J. (2010). Inflexible and indifferent alcohol drinking in male mice. Alcohol. Clin. Exp. Res. 34, 1219-1225. doi: 10.1111/j.1530-0277.2010.01199.x

Li, S. B., Jones, J. R., and de Lecea, L. (2016). Hypocretins, neural systems, physiology, and psychiatric disorders. Curr. Psychiatry Rep. 18, 7. doi: 10.1007/s11920-015-0639-0

Lopez, M. F., Moorman, D. E., Aston-Jones, G., and Becker, H. C. (2016). The highly selective orexin/hypocretin 1 receptor antagonist GSK1059865 potently reduces ethanol drinking in ethanol dependent mice. Brain Res. 1636, 74-80. doi: 10.1016/j.brainres.2016.01.049

Lum, E. N., Campbell, R. R., Rostock, C., and Szumlinski, K. K. (2014). mGluR1 within the nucleus accumbens regulates alcohol intake in mice under limited-access conditions. Neuropharmacology 79, 679-687. doi: 10.1016/j.neuropharm.2014.01.024

Mahler, S. V., Moorman, D. E., Smith, R. J., James, M. H., and AstonJones, G. (2014). Motivational activation: a unifying hypothesis of orexin/hypocretin function. Nat. Neurosci. 17, 1298-1303. doi: 10.1038/ nn. 3810 
Mahler, S. V., Smith, R. J., Moorman, D. E., Sartor, G. C., and Aston-Jones, G. (2012). Multiple roles for orexin/hypocretin in addiction. Prog. Brain Res. 198, 79-121. doi: 10.1016/B978-0-444-59489-1.00007-0

Managò, F., Castellano, C., Oliverio, A., Mele, A., and De Leonibus, E. (2008). Role of dopamine receptors subtypes, D1-like and D2-like, within the nucleus accumbens subregions, core and shell, on memory consolidation in the onetrial inhibitory avoidance task. Learn. Mem. 16, 46-52. doi: 10.1101/lm.1177509

Marchant, N. J., Kaganovsky, K., Shaham, Y., and Bossert, J. M. (2015). Role of corticostriatal circuits in context-induced reinstatement of drug seeking. Brain Res. 1628, 219-232. doi: 10.1016/j.brainres.2014.09.004

Marcus, J. N., Aschkenasi, C. J., Lee, C. E., Chemelli, R. M., Saper, C. B., Yanagisawa, M., et al. (2001). Differential expression of orexin receptors 1 and 2 in the rat brain. J. Comp. Neurol. 435, 6-25. doi: 10.1002/cne.1190

McGinty, V. B., Lardeux, S., Taha, S. A., Kim, J. J., and Nicola, S. M. (2013). Invigoration of reward seeking by cue and proximity encoding in the nucleus accumbens. Neuron 78, 910-922. doi: 10.1016/j.neuron.2013.04.010

Millan, E. Z., Furlong, T. M., and McNally, G. P. (2010). Accumbens shellhypothalamus interactions mediate extinction of alcohol seeking. J. Neurosci. 30, 4626-4635. doi: 10.1523/JNEUROSCI.4933-09.2010

Millan, E. Z., Reese, R. M., Grossman, C. D., Chaudhri, N., and Janak, P. H. (2015). Nucleus Accumbens and posterior amygdala mediate cue-triggered alcohol seeking and suppress behavior during the omission of alcohol-predictive cues. Neuropsychopharmacology 40, 2555-2565. doi: 10.1038/npp.2015.102

Mokdad, A. H., Marks, J. S., Stroup, D. F., and Gerberding, J. L. (2004). Actual causes of death in the United States, 2000. JAMA 291, 1238-1245. doi: 10.1001/jama.291.10.1238

Moorman, D. E., and Aston-Jones, G. (2009). Orexin-1 receptor antagonism decreases ethanol consumption and preference selectively in highethanol-preferring Sprague-Dawley rats. Alcohol 43, 379-386. doi: 10.1016/j.alcohol.2009.07.002

Mori, K., Kim, J., and Sasaki, K. (2011). Electrophysiological effects of orexin-B and dopamine on rat nucleus accumbens shell neurons in vitro. Peptides 32, 246-252. doi: 10.1016/j.peptides.2010.10.023

Mukai, K., Kim, J., Nakajima, K., Oomura, Y., Wayner, M. J., and Sasaki, K. (2009). Electrophysiological effects of orexin/hypocretin on nucleus accumbens shell neurons in rats: an in vitro study. Peptides 30, 1487-1496. doi: 10.1016/j.peptides.2009.04.018

Naghdi, N., and Asadollahi, A. (2004). Genomic and nongenomic effects of intrahippocampal microinjection of testosterone on long-term memory in male adult rats. Behav. Brain Res. 153, 1-6. doi: 10.1016/j.bbr.2003. 10.027

Naqvi, N. H., Gaznick, N., Tranel, D., and Bechara, A. (2014). The insula: a critical neural substrate for craving and drug seeking under conflict and risk. Ann. N. Y. Acad. Sci. 1316, 53-70. doi: 10.1111/nyas.12415

Pascoli, V., Terrier, J., Espallergues, J., Valjent, E., O'Connor, E. C., and Lüscher, C. (2014). Contrasting forms of cocaine-evoked plasticity control components of relapse. Nature 509, 459-464. doi: 10.1038/nature13257

Patyal, R., Woo, E. Y., and Borgland, S. L. (2012). Local hypocretin-1 modulates terminal dopamine concentration in the nucleus accumbens shell. Front. Behav. Neurosci. 28:82. doi: 10.3389/fnbeh.2012.00082

Plaza-Zabala, A., Flores, A., Maldonado, R., and Berrendero, F. (2012). Hypocretin/orexin signaling in the hypothalamic paraventricular nucleus is essential for the expression of nicotine withdrawal. Biol. Psychiatry 71, 214-223. doi: 10.1016/j.biopsych.2011.06.025

Pomrenze, M. B., Millan, E. Z., Hopf, F. W., Keiflin, R., Maiya, R., Blasio, A., et al. (2015). A transgenic rat for investigating the anatomy and function of corticotrophin releasing factor circuits. Front. Neurosci. 9:487. doi: 10.3389/fnins.2015.00487

Qi, K., Wei, C., Li, Y., and Sui, N. (2013). Orexin receptors within the nucleus accumbens shell mediate the stress but not drug priming-induced reinstatement of morphine conditioned place preference. Front. Behav. Neurosci. 7:144. doi: 10.3389/fnbeh.2013.00144

Ramaker, M. J., Strong-Kaufman, M. N., Ford, M. M., Phillips, T. J., and Finn, D. A. (2015). Effect of nucleus accumbens shell infusions of ganaxolone or gaboxadol on ethanol consumption in mice. Psychopharmacology 232, 1415-1426. doi: 10.1007/s00213-014-3777-x

Rehm, J., Mathers, C., Popova, S., Thavorncharoensap, M., Teerawattananon, Y., and Patra, J. (2009). Global burden of disease and injury and economic cost attributable to alcohol use and alcohol-use disorders. Lancet 373, 2223-2233. doi: 10.1016/S0140-6736(09)60746-7

Renteria, R., Maier, E. Y., Buske, T. R., and Morrisett, R. A. (2016). Selective alterations of NMDAR function and plasticity in D1 and D2 medium spiny neurons in the nucleus accumbens shell following chronic intermittent ethanol exposure. Neuropharmacology. doi: 10.1016/j.neuropharm.2016.03.004. [Epub ahead of print]

Rewal, M., Donahue, R., Gill, T. M., Nie, H., Ron, D., and Janak, P. H. (2012). Alpha4 subunit-containing GABAA receptors in the accumbens shell contribute to the reinforcing effects of alcohol. Addict. Biol. 17, 309-321. doi: 10.1111/j.1369-1600.2011.00333.x

Richard, J. M., Castro, D. C., Difeliceantonio, A. G., Robinson, M. J., and Berridge, K. C. (2013). Mapping brain circuits of reward and motivation: in the footsteps of Ann Kelley. Neurosci. Biobehav. Rev. 37, 1919-1931. doi: 10.1016/j.neubiorev.2012.12.008

Sacks, J. J., Roeber, J., Bouchery, E. E., Gonzales, K., Chaloupka, F. J., and Brewer, R. D. (2013). State costs of excessive alcohol consumption, 2006. Am. J. Prev. Med. 45, 474-485. doi: 10.1016/j.amepre.2013.06.004

Saddoris, M. P., Sugam, J. A., Cacciapaglia, F., and Carelli, R. M. (2013). Rapid dopamine dynamics in the accumbens core and shell: learning and action. Front. Biosci. 5, 273-288. doi: 10.2741/e615

Sadeghzadeh, F., Namvar, P., Naghavi, F. S., and Haghparast, A. (2016). Differential effects of intra-accumbal orexin- 1 and -2 receptor antagonists on the expression and extinction of morphine-induced conditioned place preference in rats. Pharmacol. Biochem. Behav. 142, 8-14. doi: 10.1016/j.pbb.2015.12.005

SAMHSA (2014). Risk and Protective Factors and Initiation of Substance Use: Results from the 2014 National Survey on Drug Use and Health. Rockville, MD: Substance Abuse and Mental Health Services Administration.

Seif, T., Chang, S. J., Simms, J. A., Gibb, S. L., Dadgar, J., Chen, B. T., et al. (2013). Cortical activation of accumbens hyperpolarization-active NMDARs mediates aversion-resistant alcohol intake. Nat. Neurosci 16, 1094-1100. doi: 10.1038/nn.3445

Seif, T., Makriyannis, A., Kunos, G., Bonci, A., and Hopf, F. W. (2011). The endocannabinoid 2-arachidonoylglycerol mediates D1 and D2 receptor cooperative enhancement of rat nucleus accumbens core neuron firing. Neuroscience 193, 21-33. doi: 10.1016/j.neuroscience.2011.07.055

Seif, T., Simms, J. A., Lei, K., Wegner, S., Bonci, A., Messing, R. O., et al. (2015). D-Serine and D-Cycloserine Reduce Compulsive Alcohol Intake in Rats. Neuropsychopharmacology 40, 2357-2367. doi: 10.1038/npp.2015.84

Simms, J. A., Haass-Koffler, C. L., Bito-Onon, J., Li, R., and Bartlett, S. E. (2011a). Mifepristone in the central nucleus of the amygdala reduces yohimbine stress-induced reinstatement of ethanol-seeking. Neuropsychopharmacology 37, 906-918. doi: 10.1038/npp.2011.268

Simms, J. A., Richards, J. K., Mill, D., Kanholm, I., Holgate, J. Y., and Bartlett, S. E. (2011b). Induction of multiple reinstatements of ethanol- and sucroseseeking behavior in Long-Evans rats by the alpha-2 adrenoreceptor antagonist yohimbine. Psychopharmacology 218, 101-110. doi: 10.1007/s00213-0112451-9

Sinha, R. (2009). Modeling stress and drug craving in the laboratory: implications for addiction treatment development. Addict. Biol. 14, 84-98. doi: 10.1111/j.1369-1600.2008.00134.x

Smart, D., Sabido-David, C., Brough, S. J., Jewitt, F., Johns, A., Porter, R. A., et al. (2001). SB-334867-A: the first selective orexin-1 receptor antagonist. Br. J. Pharmacol. 132, 1179-1182 doi: 10.1038/sj.bjp.0703953

Spanagel, R. (2009). Alcoholism: a systems approach from molecular physiology to addictive behavior. Physiol. Rev. 89, 649-705. doi: 10.1152/physrev.00013.2008

Stratford, T. R., and Wirtshafter, D. (2011). Opposite effects on the ingestion of ethanol and sucrose solutions after injections of muscimol into the nucleus accumbens shell. Behav. Brain Res. 216, 514-518. doi: 10.1016/j.bbr.2010.08.032

Surmeier, D. J., Song, W. J., and Yan, Z. (1996). Coordinated expression of dopamine receptors in neostriatal medium spiny neurons. J. Neurosci. 16, 6579-6591.

Thorpe, A. J., and Kotz, C. M. (2005). Orexin A in the nucleus accumbens stimulates feeding and locomotor activity. Brain Res. 1050, 156-162. doi: 10.1016/j.brainres.2005.05.045

Trivedi, P., Yu, H., MacNeil, D. J., Van der Ploeg, L. H., and Guan, X. M. (1998). Distribution of orexin receptor mRNA in the rat brain. FEBS Lett. 438, 71-75. doi: 10.1016/S0014-5793(98)01266-6 
Urstadt, K. R., and Stanley, B. G. (2015). Direct hypothalamic and indirect trans-pallidal, trans-thalamic, or trans-septal control of accumbens signaling and their roles in food intake. Front. Syst. Neurosci. 9:8. doi: $10.3389 /$ fnsys.2015.00008

WHO (2014). Global Status Report on Alcohol and Health-2014. Geneva: World Health Organization.

Wilden, J. A., Qing, K. Y., Hauser, S. R., McBride, W. J., Irazoqui, P. P., and Rodd, Z. A. (2014). Reduced ethanol consumption by alcohol-preferring (P) rats following pharmacological silencing and deep brain stimulation of the nucleus accumbens shell. J. Neurosurg. 120, 997-1005. doi: 10.3171/2013.12.JNS 13205

Wu, M., Zhang, Z., Leranth, C., Xu, C., van den Pol, A. N., and Alreja, M. (2002). Hypocretin increases impulse flow in the septohippocampal
GABAergic pathway: implications for arousal via a mechanism of hippocampal disinhibition. J. Neurosci. 22, 7754-7765.

Conflict of Interest Statement: The authors declare that the research was conducted in the absence of any commercial or financial relationships that could be construed as a potential conflict of interest.

Copyright (c) 2016 Lei, Wegner, Yu, Mototake, Hu and Hopf. This is an open-access article distributed under the terms of the Creative Commons Attribution License (CC $B Y)$. The use, distribution or reproduction in other forums is permitted, provided the original author(s) or licensor are credited and that the original publication in this journal is cited, in accordance with accepted academic practice. No use, distribution or reproduction is permitted which does not comply with these terms. 